\title{
“Comparing the Fatality Risks in United States Transportation Across Modes and Over Time”
}

\author{
Ian Savage \\ Department of Economics and the Transportation Center \\ Northwestern University \\ 2001 Sheridan Road \\ Evanston IL 60208, USA \\ ipsavage@northwestern.edu
}

Published in Research in Transportation Economics: The Economics of Transportation Safety, volume 43(1), pages 9 -22, 2013. 


\begin{abstract}
$\underline{\text { Abstract }}$
This paper analyzes the transportation fatality risk in the United States. The analysis is in two parts. The first part compares the relative risks of the different modes based on data for the decade from 2000 to 2009. The second part is a time-series analysis for each mode using annual data from 1975 to 2010. By almost any measure, transportation is considerably safer now than it was in the mid 1970s. The improvement is especially noticeable for commercial modes such as aviation, railroads and maritime. Even the risks from private highway driving have halved during the past thirty-five years.
\end{abstract}

Keywords: Safety - Transportation - United States

JEL Codes: R41 
This paper analyzes the transportation fatality risk in the United States. The analysis is in two parts. The first part compares the relative risks of the different modes based on data for the decade from 2000 to 2009. Using data from an entire decade minimizes any misleading comparisons that might results from using data for a single year. This is because for some modes there are extreme fluctuations in annual fatality counts due to rare catastrophes that can claim tens, and sometimes hundreds, of lives. The second part is a time-series analysis for each mode using annual data from 1975 to 2010. The choice of 1975 as the starting point was primarily determined by data availability. The federal government established a number of transportation safety agencies in the late 1960s and early 1970s and this resulted in an expansion of data collection.

The focus on fatalities is primarily motivated by a greater confidence that this measure of safety is reported more consistently and accurately across modes and time. In general, crosssectional and time-series comparisons in fatalities are also indicative of differences in non-fatal injuries, illnesses, and property damage. Albeit that the correlation is not perfect. In particular, fatalities are a poor measure of some of the environmental risks associated with the transportation of oil products and hazardous materials. In addition many of the advances in safety in recent decades have focused on "crashworthiness" whereby design changes have been made to increase the survivability of crashes and mitigate the severity of injuries. Consequently it is possible that a reduction in fatalities may be partly compensated for by an increase in the number of injuries.

Often fatality data is problematic for analytical purposes because fatalities are generally few in numbers, and in some modes occur in very rare multi-fatality events. As a consequence there are often considerable year-to-year fluctuations, and analyses comparing different modes or time periods suffer from large standard errors and poor statistical significance. However, the United States is a large country with an average population in the decade from 2000 to 2009 of 295 million. Therefore, while the risks are low, the annual count of fatalities is substantial in most modes. While passenger fatalities in scheduled aviation, passenger rail, ferryboat and bus modes are dominated by rare catastrophes, other classes of fatalities within these modes are characterized by many single-fatality events that are more consistent in number from year to year. Examples include fatalities resulting from on-demand air taxis, private flying, private boating, collisions between trains and vehicles at rail-highway grade crossings and between trains and pedestrians who are trespassing on the tracks.

\section{Cross-Sectional Analysis}

The analysis in this section is based on calculating an average annual number of fatalities using data for the ten-year period from 2000 to 2009. An appendix gives details on the sources of the data.

\subsection{An Overview}

In an average year between 2000 and 2009, 43,239 people died in transportation incidents. This is an annual risk of 1 in 6,800 based on the number of U.S. residents (of course, 
some U.S. residents die in transportation incidents elsewhere in the world, and some foreign residents die in incidents within the United States).

Transportation risks accounted for about $1.78 \%$ of the 2.43 million annual deaths from all causes in the United States. This amounted to 1 in every 56 deaths. However, among "unintentional injury deaths" - those deaths not caused by aging, disease, suicide and homicide transportation incidents were the most prevalent cause of death. Transportation-related fatalities represented 38\% of all "unintentional injury deaths." Moreover, they were equivalent in number to the sum of the next two most prevalent causes, which were falls and poisonings.

One might argue that transportation equipment, and in particular the motor vehicle, must be the most dangerous machines that we interact with on a daily basis. The annual toll in motor vehicle crashes exceeds the deaths resulting from the next most dangerous mechanical device, firearms, by about 40\% (based on data from 2000 to 2007, with total firearms deaths calculated from a combination of homicides, suicides, law enforcement acts and accidental discharges).

A categorization of the 43,239 fatalities by mode and type of user is shown in Table 1 . Users are divided to two broad categories. The first is private transportation that encompasses walking, bicycles, motorcycles, cars and light trucks, recreational boating and private flying. Here the user is in control of their vehicle, or is a passenger in such a private vehicle. The other broad category is commercial transportation where passengers or freight shippers contract with transportation providers. Victims in the commercial category can be either users (primarily passengers), employees of transportation companies, or bystanders who are fatally injured by debris or hazardous materials releases. There is also an intersection of the two categories when there is a collision between a private user and a commercial carrier.

Figure 1 provides a diagrammatic presentation of the magnitude of the various categories. Incidents that solely involved private users accounted for the vast majority (85.2\%) of total transportation fatalities. Some of these incidents are single-vehicle crashes and others are when multiple private users collide with each other. About 1 out of every 7 (14.8\%) transportation fatalities occurred in incidents involving commercial transportation. The vast majority, 83\%, of the victims of commercial transportation-related incidents were actually private users who were in collision with a commercial carrier. Collisions between private highway users and trucks, taxis and buses resulted in an average loss of 4,467 private user lives each year. In addition, 247 motorized private users, and 68 pedestrians, died each year in collisions with trains at railhighway grade crossings. A further 524 pedestrians died each year as a result of trespassing on train tracks at locations away from formal crossings.

Consequently only $2.5 \%$ of the total fatalities were people directly involved in the production or consumption of commercial transportation services as an employee or passenger. The implication for economists is that two extensive field of safety research - industrial organization analysis of firms' commercial safety choices and labor economics' examination of workplace safety - bear on only a small minority of total fatalities. 


\subsection{Highways}

We now turn to look at individual modes, and start by analyzing the highway sector. Nearly all of the total fatality risk occurs in this sector. Deaths on the highway were $94.4 \%$ of the national total. If highway deaths that occurred in collisions at rail-highway grade crossings were included the total would be even higher at $95.2 \%$.

In structuring the discussion, we will follow the distinctions that are usually made by traffic safety engineers who look at the role of the vehicle, the roadway, and the driver in crash causation (Haddon, 1972). We will first look at how crashes frequency, characteristics and severity varied by the type of vehicle or vehicles involved.

Approximately three-quarters (73.7\%) of total highway fatalities were occupants of automobiles and light trucks. The light truck category encompasses passenger minivans, pickup trucks and sport-utility vehicles in addition to light freight and commercial vehicles. We have grouped these two categories together because household passenger vehicles may fall into either category. Moreover, Oster and Strong (2013) in this volume show that the occupant fatality rates for these two categories of vehicle are approximately the same and have been similar for several decades.

It is notable that greater than half (55\%) of the fatalities suffered by occupants of automobiles and light trucks occurred in incidents that did not involve another vehicle. These single-vehicle crashes occur when a vehicle rolls over without a prior collision, strikes a fixed object at the side of the road, strikes an animal or debris in the roadway, or catches fire. The proportion of total occupant fatalities that occurred in single vehicle crashes is much higher for light trucks (66\%) than it is for automobiles (47\%). Light trucks tend to have a higher center of gravity than automobiles resulting in a greater propensity to roll over.

The remaining half of automobile occupant fatalities and third of light truck fatalities occurred in multi-vehicle crashes. Because automobiles and light trucks have similar overall occupant fatality rates, light trucks had a lower rate of occupant fatalities in multi-vehicle collisions. This might be expected given the generally greater mass and size of light trucks compared with automobiles.

An astonishing 9.9\% of all highway fatalities were motorcyclists. As with automobiles, about half of all motorcyclist fatalities occurred in single-vehicle incidents. When a motorcycle is involved in a collision with another vehicle, the motorcyclist invariably receives more serious injuries. The ratio of fatalities in two-vehicle collisions was 70 motorcyclist fatalities for each fatal injury sustained by the occupant of the other vehicle. Motorcycles have been a source of particular concern in the past decade as they have become more popular, with vehicle miles increasing by as much as $75 \%$ and there has been a proportionate increase in fatalities.

Occupants of large trucks, freight vehicles weighing at least 10,000lbs, represented $1.7 \%$ of total highway fatalities. Three-quarters of the truck occupant fatalities occurred in singlevehicle incidents, with two-thirds of these occurring in incidents where a truck jack-knifed or rolled on its side without involvement in a prior collision. In incidents where there is a collision 
between a truck and another highway user, the laws of physics would suggest that truck occupants are much better protected than the other road user. Indeed in incidents of a collision between a truck and some other highway user (including pedestrians) there were 23 other highway user fatalities for each truck occupant fatality.

Occupants of buses (vehicles with a capacity of 10 passengers and greater) represented just $0.1 \%$ of the total fatalities. The average annual number of fatalities was roughly 40 , with employees of bus companies representing a quarter of the total. Long distance scheduled and charter service accounted for $44 \%$ of total bus fatalities, school buses $23 \%$, urban transit $11 \%$, and the remaining $22 \%$ encompassed a myriad of other types of bus service such as private workplace and church buses.

The type of highway has a significant effect on the fatality risk. Federal data on both fatalities and the amount of vehicle miles of travel is categorized by the functional class of the road (Interstate highway, arterial, collector or local) and whether the highway is in an urban or rural area. Based on data from 2009, highways in rural areas have a fatality risk that is 2.7 times greater than that in urban areas. In general the lower average speeds, greater provision of lighting, greater deployment of traffic control devices and fewer curves in urban areas more than compensate for factors such as the greater number of intersections and the presence of pedestrians. The safest functional class of roads is the Interstate Highway System. This type of highway has a fatality rate per vehicle mile that is about half the national average for all roads. The elimination of intersections and the construction of a median between the vehicles moving in opposite directions reduces the frequency of crashes, albeit that the crashes that do occur tend to be more severe due to the higher travel speeds. In general, the riskiest types of highways are those in rural areas that do not have a middle division between oncoming traffic.

We finally turn to the characteristics of the victims. Of the occupants of automobiles and light trucks who received fatal injuries approximately $70 \%$ were the driver of the vehicle and $30 \%$ were passengers in the vehicle. About 1 in 7 (14.6\%) of total highway fatalities were not occupants of motor vehicles or motorcycle riders. This category is primarily (85\%) composed of pedestrians, but also includes bicyclists, other non-motorized users, and those who may be living or working adjacent to the highway. Greater than $90 \%$ of pedestrian fatalities occurred in collisions with automobiles and light trucks.

A driver's gender and age has a considerable effect on the fatality risk. Some basic insights can be found by comparing 2009 data on the age and gender distribution of motor vehicle and motorcycle driver fatalities with the gender and age distributions of the population in general. Based on this comparison, males face a risk that is three times higher than that for females. Of course, one would ideally wish to examine gender differences based on the proportion of each gender that possesses a drivers' license and the amount of driving that they do. Looking at the same risk measure by age reveals that most age groups have broadly the same fatality risk with the exception of younger people between the ages of 18 and 29. The risk for people in this age range is $50 \%$ to $90 \%$ higher than average.

Irrespective of age and gender, about a third of highway fatalities occur in incidents in which at least one of the involved drivers/motorcycle riders was impaired by alcohol 
consumption in excess of the legal alcohol-blood limit of 0.8 grams per deciliter. The proportion of incidents that involve alcohol has not changed in the past two decades. In addition to alcohol impairment there is a continuing concern about drivers whose reactions and judgment are impaired by tiredness, and an increasing debate about drivers being distracted from the driving task as new electronic communication and listening devices supplement traditional in-car distractions such as tuning the car radio.

Highway users can also affect their fatality rate by their choice of whether or not they fasten their safety belt. The National Highway Traffic Safety Administration (2010) estimated that $16 \%$ of vehicle occupants did not use a seat belt in 2009 . However, these non-belt users are overrepresented in the fatality totals. Almost half (49.2\%) of fatally-injured automobile and light truck occupants were not wearing a seat belt or using a child safety seat at the time of their death.

\subsection{Mainline railroads}

Compared with highways, other modes had considerably lower annual fatality counts. However, the totals are still substantial. Mainline railroads claimed an average of 876 lives a year. Maritime fatalities were of a similar magnitude at an average of 833 a year, and aviation fatalities were only slightly less at 646 a year. Aviation and maritime are somewhat different from railroads in that $85 \%$ of both aviation and maritime fatalities were associated with private usage in the form of private flying (known as "general aviation") and recreational boating, whereas the land-based railroad mode had a substantial number of collisions with highway users and pedestrians.

Mainline railroads comprise the freight railroad system, Amtrak inter-city trains and commuter passenger trains. Incidents involving urban subway, elevated and light rail transit systems are reported to a separate federal agency and are discussed in a later section.

The vast majority of the risk was suffered by people other than those involved in the production and consumption of rail service. The breakdown of the average of 876 annual fatalities was:

490 Trespassers (primarily pedestrians) at places other than grade crossings,

281 Motorized highway users at grade crossings,

68 Pedestrians and non-motorized highway users at grade crossings,

26 On and off-duty employees and contractors working on the railroad,

7 Passengers on trains,

$4 \quad$ Bystanders not on railroad property.

Pedestrians and other non-motorized persons constituted almost two-thirds (64\%) of total railroad fatalities. There were additional fatal collisions between trains and pedestrians that are not accounted for in our analysis because prior to July 2011 railroads were not required to report suicidal acts to the federal government. Professionals working in suicide prevention estimate that about $1 \%$ of the approximately 33,000 annual suicides in the United States involve a train (coding of data from death certificates reported by local medical examiners to the federal government is sufficiently ambiguous to prevent calculation of a definitive number). Even though suicides were not, at the time of our analysis, supposed to be reported by the railroads, 
there is evidence that some suicides have been included in the trespasser fatality numbers. This is because the intentions of some victims are not always readily apparent, and federal trespassing data was not, during the time period under study, always reconciled with decisions on the cause of death made by local medical examiners, especially when there was a time lag between the incident and the medical examiner's final report.

George (2008) matched up 60\% of the trespassing fatalities in the federal database that occurred in 2002, 2003 or 2004 with the records held by local coroners and medical examiners. He found that in $17.5 \%$ of the available cases the coroner had used the words "suicide" or "intentional" somewhere in their report. An additional 5.2\% of cases contained a written narrative that would suggest suicide as a motive. If the proportions found by George are applied to the annual total of 490 trespassers, approximately 85 to 110 are probably suicides. If railbased suicides are about $1 \%$ of the 33,000 annual suicides, it is likely that unreported suicides would have added 220-245 fatalities to the annual toll on the railroad. This would suggest that total railroad-related fatalities would have been in the range of 1,095 to 1,120 a year.

Fuller and Savage (2012) analyzed a dataset on pedestrian and bicyclist fatalities in the Chicago metropolitan area. The data for the years from 2004 to 2011 was derived from a wider array of sources than the federal government's database. They found that $47 \%$ of non-motorized fatalities were likely suicides, $22 \%$ were due to non-suicidal collisions at highway grade crossings or at pedestrian walkways between platforms at stations, and the remaining $31 \%$ were non-suicidal events occurring at locations other than stations and grade crossings.

The annual toll to trespassers, and pedestrians and other non-motorized users at crossings, while varying from year-to-year, did not trend either upwards or downwards over the decade. In contrast the number of motorized highway user fatalities at grade crossings declined markedly. The absolute number of fatalities fell by 50\% from 361 in 2000 to 180 in 2009 . In 2009 there were $40 \%$ fewer motorized and non-motorized crossing fatalities than trespassing deaths.

When suicides and pedestrian fatalities at grade crossings are included with trespassers, it is clear that, numerically, the greatest safety problem facing the railroads is trains striking pedestrians. That said, pedestrian incidents rarely lead to physical damage to the train or serious injuries to passengers or employees on the train. (The mental injuries suffered by locomotive engineers and train conductors who witness these events are another matter entirely.) In contrast there is a genuine concern that collisions with motor vehicles can lead to catastrophic consequences including the derailment of the train. At Glendale, California in 2005 a highway user drove a sport-utility vehicle off of a crossing onto the adjacent tracks leading to collision involving two passenger trains and a freight train and the deaths of 10 passengers and one employee. In 1999 a collision between an Amtrak train and a truck at Bourbonnais, Illinois led to the deaths of 11 train passengers.

Relative to trespasser and crossing incidents, fatal incidents affecting other groups were quite rare. Half of the 26 employee and contractor fatalities each year occurred in maintenance activities including the maintenance of track and structures. Many of these did not involve a moving train. Train crews do face risks in collisions and derailments, but they also face risks 
while coupling and uncoupling locomotives and train cars, and from falling while getting on or off rolling stock or while walking beside the track.

Over the whole decade, there were a total of 70 passengers-on-trains fatalities. Half of the fatalities occurred in two incidents, the 10 passenger fatalities in the 2005 Glendale, California crash described above, and the 24 passengers who died at Chatsworth, California in 2008 when a commuter train passed a signal at danger, and collided head-on with a freight train.

Finally there were a total of 38 people in the decade who were adjacent to the railroad and fatally injured by flying debris or the release of hazardous materials. Eight of the offrailroad fatalities occurred in a single incident at Graniteville, South Carolina in 2005 when a two-train collision led to the release of chlorine gas.

\subsection{Maritime}

Maritime data includes all incidents in United States territorial waters and inland waterways and lakes, and all incidents involving U.S.-registered vessels anywhere in the world. The data excludes deaths due to suicide, homicide, altercations onboard and passengers who die onboard from pre-existing medical conditions. It also excludes deaths in shore-side port facilities, and persons who are walking on docks and fall into the water and drown.

The annual maritime death toll averaged 833 . The vast majority (85\%) of the deaths involved private recreational vessels which range in size from large luxury private yachts to personal water craft (commonly referred to by the commercial trade names "jet ski" and "wave runner"), row boats, kayaks and canoes. The remaining fatalities were in a variety of commercial vessels that range from small vessels offering fishing and diving trips through tugs and commercial fishing vessels to large passenger ships, oil tankers and container ships. About $55 \%$ of commercial-sector fatalities occurred in "vessel casualties" where the vessel also sustained damage, but $45 \%$ were in circumstances where the vessel did not sustain any damage such as would occur if a person fell overboard and drowned. Approximately two-thirds of commercial vessel casualties were employees and one-third were passengers. Of the passenger fatalities on commercial vessels, a third of them occurred in scuba diving and snorkeling incidents.

\subsection{Aviation}

Aviation crash data includes incidents occurring in United States airspace and incidents overseas involving U.S.-registered aircraft. Traditionally aviation crash and fatality rates are reported after excluding incidents of suicide, sabotage and terrorism. Usually this exclusion only affects a handful of suicide-related private general aviation crashes each year. Of course, the past decade included the hijackings of four commercial aircraft on September 11, 2001 that resulted in the deaths of the 265 persons onboard and approximately 2,730 persons on the ground. Excluding suicide and terrorism cases, the categorization of the average annual fatalities was:

549 Private flying ("general aviation”),

50 Passengers and crew on large (10 or more seats) scheduled commercial aircraft, 
42 Passengers and crew on small (fewer than 10 seats) non-scheduled commercial aircraft (on-demand air taxis, medical flights etc.),

2 Passengers and crew on small (fewer than 10 seats) scheduled commercial aircraft,

2 Persons on the ground,

1 Crew member on large (10 or more seats) non-scheduled commercial aircraft (primarily freight operations).

The vast majority of the annual aviation fatalities (85\%) occurred in incidents involving private flying. Private flying covers a range of activities. The Federal Aviation Administration's (2009) annual survey of general aviation activity indicates that $41 \%$ of flight hours are for personal recreation, $24 \%$ are business trips, and $17 \%$ are instructional. Aerial businesses such as photography, mapping, surveying and crop dusting account for most of the remaining 18\% of flight hours.

Nearly all of the fatalities in general aviation occurred in single-aircraft incidents. Oster, Strong and Zorn (1992) indicate that unforced pilot errors account for the majority of general aviation crashes, and a majority of these errors are due to the exercise of poor judgment by the pilot. In contrast mechanical problems and bad weather are much less important in explaining incidents. There have been occasions when two private aircraft collide in mid-air, and in some cases a private aircraft has collided with a commercial aircraft. In the past decade there were only a few collisions between private and commercial aircraft, and all of them involved a commercial aircraft with less than 10 seats that was providing unscheduled service. In prior decades there had been some high fatality events when a small aircraft collided with a large passenger aircraft. (Indeed, in 2006 there was a collision between a new U.S.-registered private aircraft that was being delivered from a Brazilian factory and a Brazilian passenger aircraft in Brazilian air space. The 154 fatalities on the Brazilian plane are not included in this analysis.)

Of the 501 total fatalities in the decade onboard scheduled commercial large aircraft flights, 446 occurred in four incidents. In 2000, 88 persons died after a mechanical failure on an aircraft over the Pacific Ocean off the California coast. In 2001 an aircraft crashed into a neighborhood of New York City with the deaths of 260 onboard and 5 persons on the ground following structural failure caused by excessive rudder use to counteract turbulence. In 2006, 49 people died when the pilots of an aircraft mistakenly selected a runway that was too short during a take-off from Lexington, Kentucky. Finally, in 2009, 49 persons aboard and 1 person on the ground died due to pilot error in responding to bad weather when an aircraft was approaching to land at Buffalo, New York State.

In the past there have been high fatality events involving large aircraft in non-scheduled operations. These operations include charter flights and military transport flights by civilian aircraft. However, there have not been any such incidents since the mid 1990s. In recent times, large aircraft fatal crashes in non-scheduled operation have primarily been air cargo flights.

Each year about 25 passengers and 17 crew members died in incidents involving nonscheduled commercial service by small aircraft. The vast majority (75\%) of the total flight hours for this category of flying are on-demand air taxi operations. Many of these operations are in 
remote areas with difficult flying conditions such as in Alaska. The next largest category is medical transport flights. These flights represent $17 \%$ of flight hours by non-scheduled small aircraft. In 2009, the National Transportation Safety Board undertook an investigation of medical flights involving helicopters in response to series of fatal incidents.

\subsection{Rail Transit}

There are broad reporting requirements for rail transit fatalities. While transit deaths exclude those from illnesses and medical conditions, rail transit statistics include victims of crime, and other incidents not involving a moving train such as persons who fall down flights of stairs in a subway station. There is also required reporting of suicides, although the approximately 22 such annual fatalities are not included in Table 1.

Each year on average there were 8 deaths of passengers while onboard trains, 15 passenger deaths at stations, and 3 employee deaths. In addition there was an average of 8 highway user fatalities from collisions at rail-highway grade crossings and 34 trespassers

fatalities. In recent decades there has been a resurgence of light-rail transit service. Some of these systems feature on-street running, or reserved rights-of-way adjacent to the highway. There is a growing concern that the reemergence of streetcars is a hazard to unwary motorists and pedestrians, and that there has been an increase in highway-light rail grade crossings at a time when mainline railroads have been working to reduce the number of crossings.

\subsection{Pipelines}

Pipelines are an often forgotten transportation mode, yet they account for a fifth of freight ton-miles (Eno Transportation Foundation, 2007). The primary goods moved are crude oil, oil products and natural gas. Natural gas pipelines encompass both long-distance transmission lines and local distribution lines. While there were a handful of employee deaths each year, the majority of the risk is to bystanders with an average of 12 bystanders killed each year primarily in fires and explosions. Most of the risk was in local gas distribution.

\subsection{Cross-Modal Passenger Fatality Risk Comparisons}

The preceding discussion has presented the number of fatalities in absolute terms and without reference to the relative amounts of travel. Table 2 presents an average passenger fatality rate per billion passenger miles for seven different modes for the 2000 to 2009 period. The numerator for commercial modes only includes onboard passenger fatalities and excludes fatal injuries to employees. The choice of a denominator for such a comparison is always controversial. We have used passenger miles as the exposure variable because it allows a safety comparison that might be made if a person was choosing between modes for a given journey. Engineers might argue for the use of more technology-driven denominators such as passengerhours or vehicle-hours to account for different vehicle capacities and the average speed of travel.

Commercial aviation, which is defined here as scheduled service provided in a U.S.registered aircraft of more than 10 seats in domestic and international service ("Part 121 scheduled service”) was the safest mode of travel at 0.07 fatalities per billion passenger miles. A 
person who took a 500 mile flight every single day for a year, would have a fatality risk of 1 in 85,000 .

While commercial aviation has long been recognized as the safest mode of transportation, passengers on buses had a fatality rate that was almost as good. Passengers on buses of all types holding more than 10 passengers had a fatality rate of 0.11 per billion passenger-miles or about $65 \%$ greater than that for aviation.

It would appear that urban mass transit rail had a fatality rate about double that for buses, but it should be remembered that the rail mode includes crime victims, whereas bus casualties are only those that occur in a crash or if a person falls within the vehicle.

Mainline passenger rail service had a considerably worse fatality rate at 0.43 per billion passenger miles. This is about four times the risk for bus passengers and six times the risk in commercial aviation.

Deaths on scheduled ferry boats are rare, but the number of passengers each year is relatively small. Consequently, when the decade includes a major incident, the risks can look large at 30 times the risk for bus passengers. All of the 11 ferry passenger deaths in the past decade occurred in one incident in New York City in 2003 when a ferry approached a dock at faster than normal speed and struck the jetty.

Persons who were the driver of, or a passenger in, an automobile or light truck faced a fatality risk of 7.3 per billion passenger-miles. A person who was in a motor vehicle for 30 miles every day for a year faced a fatality risk of about 1 in 12,500. Relative to mainline trains, buses and commercial aviation the risk was 17, 67, and 112 times greater, respectively. Of course, unlike the commercial modes where passengers are victimized randomly, the risk to individual highways users varies considerably depending on age, alcohol consumption and the type of road used. To the extent that aviation is disproportionately used by business travelers who are typically older, travel at times of day when there is a lesser incidence of impaired drivers, drive larger vehicles, and use Interstate highways, the comparison between driving and aviation would be less unfavorable.

Finally, motorcycles had a fatality rate of 212 per billion passenger miles. A motorcyclist who traveled 15 miles every day for a year, had an astonishing 1 in 860 chance of dying. The rate per passenger mile was 29 times that for automobiles and light trucks.

\subsection{Cross-Modal Employee Fatality Risk Comparisons}

The annual fatality risk per 1,000 employees in different industry segments is shown in Table 3. The data are for 2009 and are obtained from the Department of Labor. Reporting firms are classified into industrial groups using the North American Industry Classification System. Consequently, there may not be a perfect alignment of this data with the modal data that was discussed earlier in this section. In addition some fatalities that occur in ancillary activities such as maintenance would be included in this data set but not in the data on crashes that are reported to the Department of Transportation. Table 3 displays the industries in a descending order of 
fatality risk. For purposes of comparison, leading non-transportation industry segments are also included, and are shown in italics.

One might imagine that transportation would be a relatively risky industry in which to work as it is characterized by outdoor activities involving heavy moving machinery in locations that can be far away from immediate medical care. Indeed, fishing is one of the most hazardous occupations in the United States with an annual fatality rate of 1 in 115 . The risk is about 30 times that of truck drivers. The next most dangerous transportation occupation is driving a taxi or limousine with an annual fatality risk of 1 in 1,600. More than half of the fatalities occur in assaults and violent acts. Excluding homicides the risk to taxi and limousine drivers is comparable to that of truck drivers.

Even the more moderate fatality risks in trucking and non-fishing maritime transportation are quite high in comparison with some other industries that might appear to be quite comparable in terms of the type of risks that might be faced. Trucking and maritime fatality rates are twice as high as those in the mining and construction industries. Working in the railroad and aviation industry is much less risky. The risks are only one fifth of those in the trucking industry. But even in the comparatively less risky railroad and aviation industries, employee fatality rates are still twice those of working in manufacturing.

\section{Time-Series Analysis}

The second part of the paper is an analysis of the trends in fatalities and fatality rates across the 36 year period from 1975 to 2010 . A series of figures is used to plot the data and illustrate the trends. A supplementary appendix containing the data for the figures is available from the author.

\subsection{Highways}

Figure 2 shows the trends in highway fatality rates per 100 million vehicle miles. The rate for all fatalities (both vehicle occupants and pedestrians) is shown as the solid line. The rate in 2010 is just one-third of that in 1975 (1.11 versus 3.35 fatalities per 100 million vehicle miles). The 1980s and early 1990s were the era of the greatest rate of improvement. Rates improved at a more modest pace between about 1993 and 2006. There is some indication that the rate of improvement has increased in very recent times, starting in about 2006.

The rate for large trucks is shown as the dashed line. This is calculated as the number of deaths in incidents in which a truck is involved divided by truck miles. The rate includes fatal injuries sustained by both truck occupants and other highway users, with the latter being $85 \%$ of the total. One should not necessarily infer that the truck was at fault in all of the included multivehicle or truck-pedestrian incidents. The data for trucking are not shown for 2009 or 2010 due to a change in the methodology used by the Federal Highway Administration (FHWA) for estimating total national truck miles. 
Truck-involved fatality rates were increasing in the period between 1975 and 1979 . Since 1980 there has been a continuous improvement. Indeed the truck-involved fatality rate has improved at a faster rate than that for all motor vehicles in general. Consequently, while the fatality rate in truck-involved crashes in 1975 was 65\% higher than that for all motor vehicles (5.51 versus 3.35 fatalities per 100 million vehicle miles), by 2008 it was only $50 \%$ higher (1.87 versus 1.26 fatalities per 100 million vehicle miles). The strong improvement in the truckinvolved fatality rate, especially in the 1980s, stands in contrasts to the fears expressed by opponents of the 1980 economic deregulation of interstate trucking (that is to say, trucking that crosses state lines). The opponents of deregulation argued that competition would result in the entry of inexperienced firms, and that existing firms would reduce their financial commitment to safety so as to remain competitive. While fatality rates did not get worse, the early 1980s were also a very active era for legislative action. Federal and state governments promulgated new truck safety regulations, expanded programs of inspecting trucks at the roadside and auditing the safety practices of truck firms, and implemented stricter rules for the issuing of licenses to commercial vehicle drivers.

While fatality rates for both trucks and for all vehicles in general may have fallen, the number of fatalities has not declined as quickly because the amount of highway traffic has increased substantially. Total vehicles miles travelled increase by $123 \%$ between 1975 and 2010, and truck miles increased by 168\% between 1975 and 2008. Figure 3 shows the annual fatality count for all highway users (solid line) and in truck-involved crashes (dashed line). Declines in the absolute number of total fatalities occurred in three time periods: 1980-1983, 1988-1992, and since 2005. In the latter period, the substantial increase in gasoline prices and the economic troubles starting in 2008 led to a slowing (and even a reversal) of the long-term growth in vehicle miles travelled. From 1992 to 2005 the increase in travel more than counteracted the decline in fatality rates resulting in an increase in total fatalities.

Fatalities in truck-involved incidents have remained reasonably constant in the range of 4,500 to 5,500 for most of the period. The increased amount of truck traffic approximately counterbalanced the improvement in the fatality rate. Fatalities were less than 4,000 in 2009 and 2010, but the severe economic recession had led to considerably reduced truck mileage (the total mileages for combination trucks in 2009 and 2010 were $8.9 \%$ and 4.5\%, respectively, below the mileage in 2007 based on the new methodology used by the FHWA).

In part the improvement in highway safety since 1975 is due to demographic changes. As the baby boom generation (those born between 1945 and 1960) has aged, the proportion of drivers that are in the high-risk 18-29 age group has fallen. According to the 1980 United States Census, 18-29 year olds represented $30 \%$ of the pool of people of driving age (taken here to be those between the ages of 16 and 79). By the 2000 and 2010 Censuses that proportion had fallen to 22\%. In addition, the United States has also continued the long term trend of becoming more urban. The FHWA reports that in 1975, 45\% of vehicle miles were driven on rural highways. By 2010 that proportion had declined to 33\%. As discussed earlier in the paper, urban roads have a fatality rate per vehicle mile that is only $37 \%$ of that on rural roads.

The chapters by Oster and Strong (2013) and Blattenberger et al. (2013) in this volume discuss both the demographic changes and other reasons for the improvement in highway fatality 
rates. The interested reader is also directed to two encyclopedic volumes by Evans (2004) and Elvik et al. (2009), both of which contain analysis and extensive reference lists to papers and reports that have explored the factors that have contributed to the improvement in highway safety.

In describing other possible reasons for why highway safety has improved, it is useful to use the concept that traffic safety can be characterized by a three by three matrix (Haddon, 1972). The categories on one axis are the driver, the vehicle, and the highway. The other axis is composed of actions before a crash ("crash avoidance"), the crash phase, and the post-crash phase.

In the crash avoidance phase there has been public policy action to improve the training of young drivers and to restrict the activities of the youngest and most inexperienced drivers. Society has also taken a strong line since the 1970s to combat driving under the influence of alcohol through public information campaigns, lowering the permissible level of alcohol in the blood, law enforcement efforts, and increasing the minimum age for alcohol consumption to 21 . Vehicle improvements that have aided crash avoidance include advances in tire technology, and the deployment of stability control and anti-lock brakes. In addition, improvements in highway construction and geometry have promoted crash avoidance.

During the crash phase, injuries have been reduced and their severity mitigated by educational programs, legal changes and law enforcement efforts that have led to a greater proportion of drivers and passengers using seat belts and child safety seats. Vehicle design changes have reduced the severity of injuries. These include the strengthening of the passenger cabin and the redesigning of interior surfaces. The design of highways has also changed over time to mitigating the harm when a crash occurs. In particular guardrails, signposts and bridge abutments have been redesigned to be less dangerous when a vehicle collides with them after having left the highway.

Finally, a significant reduction in fatality risk has come from an improved medical response in the post-crash phase. The improvement has come in the form of quicker initial response times, better equipment available in ambulances, and the use of helicopters to transport crash victims to hospital.

But there have been changes that have worked against the safety improvements. In 1975 there was a $55 \mathrm{mph}$ national speed limit that was introduced as a result of the oil crisis of 1973. The federal speed limits were subsequently relaxed in the late 1980s and abolished in 1995. Consumers also elected to drive smaller and lighter vehicles. This was due to the increased cost of gasoline in the late 1970s, and new standards for fuel economy that were imposed starting with the 1978 model year. Finally, there has been a general rollback in the number of states requiring motorcycle riders to wear helmets.

While the downward trend in fatality rates may appear to be impressive, other countries have improved at an even faster rate. In 1970 the United States was the leader in highway safety as measured by fatalities per vehicle mile. Now Australia, Canada, and countries in Scandinavia and Western Europe have lower fatality rates (International Transport Forum, 2011). Evans 
(2004, chapter 15) argues that laxer laws in the United States compared with other countries on seat belt use and driving while intoxicated have contributed to the slower rate of improvement.

\subsection{Mainline Railroads}

Fatality rates for four categories of persons on mainline railroads are shown in Figure 4. The rates have been normalized as indices with their value in 1975 set to 100 . The largest reduction in risk is for highway users (both pedestrian and motorized) at rail-highway grade crossings. The denominator of the risk is the number of motor vehicle registered. This is shown as the line with the square markers. The risk has declined dramatically and the risk is now only $15 \%$ of what it was in 1975 . The reduction in risk is much greater than the $66 \%$ improvement witnessed elsewhere on the highway, and illustrated in Figure 2. The risk reduction at railroad crossings has been due to a combination of factors: railroad line abandonments, the closing of some crossings on lines that remained open, a federally-funded program to install warning lights and gates at crossings, and a public information campaign that is jointly promoted by the railroads, highway authorities and police departments (Mok and Savage, 2005; Savage, 2006). The reduction in risk was particularly noticeable in the late 1970s, and during the 1990s.

In contrast to the success story at crossings, improvement in the risk to trespassers has been more modest. The rate of trespasser fatalities relative to the U.S. resident population is shown as the solid line with the star markers. The rate is now about $25 \%$ less than what it was in 1975. In part this may be explained by line closures and changes in land use patterns over time that mean that people now live and work some distance from the nearest train tracks, whereas until the 1950s settlements were clustered around railroad lines. Trespassers also tend to be males in their 20s and 30s, and as the baby boom generation has aged a smaller proportion of the population is in the age range that has a greater proclivity to trespass on the railroad (Savage, 2007).

The considerable reduction in risk for highway users at grade crossings, and the small reduction in trespassing risk have led to a reversal in the absolute level of fatalities in these two categories. In the late 1970s (1975-79) crossing fatalities exceeded trespasser deaths by a ratio of 2.4 to one. In 1997 the number of trespasser fatalities exceeded the number killed in collisions at grade crossings for the first time since 1941. By 2010 the number of crossing fatalities was $40 \%$ less than the number of trespasser fatalities.

The rate of on-duty employee deaths per employee hour, shown as the solid line without markers, has steadily improved over time, and is now about $40 \%$ of what it was in the 1970 s.

The rate of passenger deaths per passenger mile is shown as the dashed line. Because passenger fatality data are dominated by rare high-fatality events, the data are shown as an 11year moving average with the data plotted at the mid-point year. That is to say that the data plotted as equaling 100 in 1975 is the average fatality risk for the years 1970 to 1981 . Even with a lengthy moving average, the data are dominated by the 1972 collision between two commuter trains in Chicago that resulted in 45 passenger fatalities, and a 1993 incident when an Amtrak train plunged from a damaged bridge into a bayou near Mobile, Alabama with the deaths of 42 passengers. The bridge had been damaged as a result of a barge colliding with it. 
Another perspective on the trends in safety can be obtained by looking at the rate of incidents per train mile. These are shown in Figure 5 as indices with the value of each series set to 100 in 1975. The rate of collisions and derailments per train mile is shown as the solid line without markers. The rate of these incidents increased rapidly in the late 1970s. Evidence suggests that the collision and derailment rate had been increasing since the 1960s. The increase coincided with the severe financial crisis experienced by the railroad industry in the 1960s and 1970s. After economic deregulation in 1980 the commercial freedom afforded the railroads led to an improvement in their profitability and a reinvestment in track and equipment. Safety improved rapidly in the early and mid 1980s.

The improvement in collision and derailment rates is partly due to the decision by the railroads to move away from the single carload business and toward operating permanently coupled trains dedicated to moving a single commodity such as coal or intermodal containers. These latter types of trains do not need to be switched in yards, and switching is a particularly risky activity compared with line-haul movements. The dashed line represents the proportion of total train miles that are in switching movements. The proportion of total train miles that occur in yards has declined from $30 \%$ in the mid 1970 s to about $13 \%$ today.

The rate of highway user fatalities at grade crossings per train mile is shown as the solid line with the square markers. The risk has declined by $70 \%$ with the most dramatic reduction occurring in the period after 1990. When a comparison is made with Figure 4, it is clear that the reduction in fatalities in the late 1970 s and 1980 s was primarily due to a reduction in train miles and the closure of many lines in the aftermath of economic deregulation. Train miles started to increase as the economy came out of the recession of the early 1990s, but the number of crossing fatalities declined substantially. One of the factors explaining the improvement in this time period was the deployment of enhanced lighting on the front of locomotives, including a triangular pattern of lights which allows highway users to judge how far the train is from the crossing and how fast it is moving.

The rate of trespassing fatalities per train mile, shown as the line with the star markers, has not witnessed the same improvement in risk as was the case for collisions and derailments and crossing incidents. Indeed the rate is now somewhat higher than it was in 1975, albeit that it is lower than it was in the early 1990s. The large absolute number of trespasser deaths (which would be even higher if suicides were included) and the seeming lack of a substantial improvement in the risk per train mile is a great cause for concern.

\subsection{Maritime}

The absolute number of maritime fatalities has fallen substantially. The annual toll for recreational users has halved from about 1,500 deaths in 1975 to about 700 in 2010. The number of fatalities on commercial vessels also decreased from a total of almost 600 in 1975 to just less than 100 in 2010. 
Figure 6 presents indices of trends in fatality rates for both commercial traffic (shown as the solid line) and recreational use (shown as the dashed line). The value in 1975 for both indices is set to 100 .

For commercial vessels the denominator of the fatality risk is cargo ton-miles in U.S. territorial waters. The fatality risk has decreased by about $80 \%$, with nearly all the reduction in risk occurring between 1975 and 1988. The total number of fatalities has fallen substantially by 85\%. While, the amount of waterborne commerce was broadly similar in 1975 and 2007 (just prior to the great recession), there was a period from 1978 to 1995 when traffic was much higher. Cargo ton-miles have declined by $40 \%$ from their peak levels in 1980-81. This exposure measure includes both domestic movements, and the portion of import and export movements within U.S. territorial waters irrespective of whether the vessel is U.S. or foreign flagged. The use of cargo ton-miles approximates exposure to fatality risk as it reflects both the length of the voyage, and the fact that larger vessels tend to have a larger number of crew. However, it does not reflect exposure from U.S. flagged vessels operating outside U.S. waters (fatalities on board U.S.-flagged vessels outside U.S. waters are included in the fatality count). This later type of operation has declined substantially as a declining proportion of the world's merchant marine fleet is flying the American flag. In the mid 1970s there were almost 900 ocean-going vessels of greater than 1,000 gross tons registered in the United States. Today the number is closer to 300.

The fatality risk in recreational boating has decreased by about $70 \%$, when the denominator used is the number of registered recreational vessels. This measure undercounts total recreational vessels as many smaller sail and row boats and canoes either do not have to be registered or are not registered by their owners. Much of the reduction in risk occurred during the 1980s. There has been a substantial campaign to promote the wearing of personal flotation devices ("life jackets") while on the water. That said, the risk seems to have stayed somewhat constant in the decade since 2000.

However, boating has increased in popularity. The number of registered private vessels has increased by $70 \%$ since 1975 . Not only has the absolute number of vessels increased, so has the per capita ownership. Part of the increase has come from the introduction of personal water craft (“jetskis”). Consequently, even though the fatality risk per registered vessel has declined by $70 \%$ since 1975 , the annual count of fatalities has only declined by $50 \%$.

\subsection{Commercial Aviation}

Comparisons of fatality risks over time in commercial aviation is challenging because fatal accidents are rare, most of the fatalities are concentrated in a few high fatality events, and the exposure to risk has increased substantially as more people are flying.

For all but two years between 1975 and 2010, the number of fatal accidents in largeaircraft scheduled service could be counted on the fingers of one hand. Consequently just one or two fewer or additional accidents in a given year will lead to a substantial variation in the accident rate. The fluctuations are even greater in the annual fatality rate because the data are dominated by a few high fatality events. Consequently, most analysts use a five-year moving average to determine trends over time. 
Analysts also have to devise appropriate measures of exposure to reflect the considerable expansion in the commercial aviation industry. A disproportionate amount of the risk in aviation occurs during the take-off and landing stages of flight, rather than when cruising at high altitude. Consequently, common measures of exposure are aircraft take-offs (referred to as “departures”), and passenger enplanements. The number of departures in scheduled service increased by $84 \%$ between 1975 and 2007 (subsequently the recession reduced the number of departures by 12\%). The number of passenger enplanements in large-aircraft scheduled service increased by an even larger amount (275\% between 1975 and 2007) reflecting the greater number of flights, the use of larger aircraft, and higher load factors (the proportion of seats that are occupied).

We will initial look at scheduled operations by large aircraft. These operations are referred to as "Part 121" after the applicable section of the federal safety regulations. Prior to 1997 this segment of the industry was defined as aircraft with 30 or more seats. Then in 1997 smaller aircraft with between 10 and 30 seats were subject to the stricter safety regulations applicable to Part 121 operations and included in this accident dataset. These smaller aircraft had previously been classified as "Part 135" operations, which we will discuss shortly. These former Part 135 operations represented a relatively small proportion of the industry, and their inclusion only increased the number of Part 121 departures by about one half of one percent.

Figure 7 shows the rate of fatal accidents per million departures for Part 121 scheduled service. The fatal accident rate in any given year is shown as the squares, with the five-year moving average (plotted at the mid-point year) shown as the solid line. The risk of a fatal accident has declined by $90 \%$ from about 0.8 per million departures in the mid 1970 s to less than 0.1 today. The inclusion of aircraft with 10-30 seats in the data from 1997 does not seem to have led to a worsening of the accident rate. Perhaps the most notable feature is the spike in the rate in 1989 and 1990. Otherwise there would seem to be a continual improvement.

The improvement in recent decades is a continuation of a long trend dating back to the development of commercial aviation in the 1920s. However, the recent rate of improvement is remarkable. Looking at the post-Second World War period from 1950 to 2010, the annualized rate of improvement in the fatal accident rate in the second half of the period (1980-2010) at approximately $8 \%$ is greater than that in the first half (1950-1980) which was approximately $5 \%$. This might be regarded as somewhat surprising. The 1950 s and 1960 s can be characterized by major technological improvements that included the introduction of first and second generation jet aircraft, developments in weather forecasting and the deployment of air traffic control systems. All of these innovations led to obvious and well documented safety improvements. Yet, recent decades have witnessed a much greater improvement despite the fact that arguably there has not been radical changes in technology that are comparable to those that occurred in the 1950s and 1960s. The changes that have occurred are perhaps more subtle such as the deployment of Doppler radar to detect windshear, continued improvements in navigation and weather detection, improved engine reliability, and an emphasis on "crew resource management" whereby cockpit crews are trained to work cooperatively in the event of an untoward event (see the paper by Oster et al. (2013) in this volume). 
An alternative measure of scheduled large aircraft safety is shown in Figure 8. This is the rate of passenger fatalities per million passenger enplanements. Fatalities to crew and persons on the ground are not included. The spike in fatal accidents in 1989 and 1990 that was noticeable in Figure 7 is not apparent here because many of the accidents in those years were low fatality events. Rather there is a spike in the mid 1990s. There was a series of high fatality events in the period from 1994 to 1996. One of these was a widely-publicized onboard fire and crash involving a controversial and rapidly expanding new entrant, ValuJet Airlines. Subsequently, there were revelations of significant operating and maintenance problems with this carrier. Critics argued that the economic deregulation of the industry, some 18 years earlier in 1978, had allowed entry by firms with inferior safety records. However, the other crashes in the 1994 to 1996 period involved established airlines, and more mainstream safety issues such as severe weather, navigational problems and equipment failure.

Despite an up-tick in the mid 1990s, the five-year moving average fatality rate has improved by an astonishing $96 \%$ between the mid 1970s and the late 2000s. The decline would have been even larger if the 1977 high-fatality collision on the ground at Tenerife, Canary Islands between two Boeing 747s, one of which was U.S. flagged, had not been classified as occurring in unscheduled service. Overall, one would be hard pressed to argue that economic deregulation had led to a diminution of safety, even though there has been entry by new firms, and most existing firms have suffered financial pressure and some have exited the industry.

Even though the number of passenger enplanements was, by 2007, almost four times what it was in 1975, the $96 \%$ reduction in the fatality rate has reduced the absolute number of average annual passenger fatalities from 166 in the mid 1970s to 39 in the decade from 2001 to 2010.

Turning to the safety of smaller aircraft, Figure 9 shows the fatal accident rate per million departures for Part 135 scheduled service. As in the earlier graph for the larger-aircraft, the rate in any given year is shown as the squares with the five-year moving average (plotted at the midpoint year) as the solid line.

Part 135 operation was, to some extent, a child of deregulation. After deregulation, the mainline airlines moved away from point-to-point service to hub-and-spoke operating strategies. Operations on some of the more lightly used spokes were provided by "commuter airlines" operating smaller aircraft. The number of Part 135 departures increased by 50\% between 1977 and 1984, and had doubled by 1996. By the mid-1980s, there was much discussion that deregulation had led to passengers on secondary routes being offered riskier, albeit more frequent and convenient, service than they used to enjoy aboard large jet aircraft. There is some truth to this. The fatal accident rate per departure in the late 1970s for Part 135 scheduled operations was about ten times that of Part 121 scheduled operations.

However, as is apparent from Figure 9, safety in this segment of the industry improved rapidly in the decade from 1975 to 1985 . The rate of fatal accidents fell from about 7 per million departures in the mid 1970s to about 2 per million departures in the mid 1980s. Oster, Strong and Zorn (1992) identify several reasons for the improvement. First, the Part 135 safety regulations were significantly strengthened in 1978. Second, the largest twenty firms in this 
segment of the industry accounted for most of the expansion of commuter operations after deregulation. These firms had a far superior safety record compared with smaller carriers, and consequently the average performance of the industry segment improved. Third, increased demand on these secondary routes led to the deployment of larger and safer aircraft. Larger turboprop aircraft increasingly replaced piston-engine aircraft that had less than twenty seats.

As demand grew still further larger turboprop aircraft, and in later years "regional jets," were deployed on secondary routes. These aircraft were subject to the stricter Part 121 regulations. Finally, as mentioned previously, in 1997 aircraft with 10 to 30 seats, were brought under the same safety regulations as the mainline jet carriers. These aircraft accounted for fourfifths of the Part 135 segment of the industry in 1996. Consequently there is an upwards discontinuity in the Part 135 data series after 1997 that is readily apparent in Figure 9. However, the accident rate for the remaining Part 135 operations has subsequently improved remarkably as can be seen when the years following 2002 are compared with the period between 1997 and 2001.

Nowadays, Part 135 only applies to firms that provide service using aircraft with fewer than 10 seats. These operations represent less than two percent of scheduled commercial aircraft flight hours, and the operations are generally confined to the most remote and operationally challenging parts of the country. The fatal accident rate per departure for Part 135 scheduled operations is about four times that of Part 121 scheduled operations. While this is a significant difference, the relative difference in risk has improved considerably compared with the situation in the late 1970s.

\subsection{Private Aviation}

Trends in the fatality risk for private flying ("general aviation”) are shown in Figure 10. Two sets are data are shown with their values in 1975 normalized to 100. The bold line indicates the rate of fatalities per aircraft flight hour. There has been a steady improvement, albeit that one might argue that the rate has been static for the past decade. The fatality rate in 2010 at 21 fatalities per million flight hours is less than half of what it was in 1975 when the rate was 47 fatalities per million flight hours.

In contrast to recreational boating that has seen an increase in popularity over time, the opposite is true for private flying. After a brief upsurge in the period between the two oil crises in the late 1970s, per capita private flight hours declined by 55\% between 1979 and 2010 . Consequently, when fatalities are shown as a rate per capita of the U.S. population (the dashed line in Figure 10), the risk has declined by $75 \%$ over time. Private flying is now inherently less risky, and in addition less people are flying. Part of the decline in popularity may be due to changes in tastes, and a continued shift of the population from rural to urban areas. However, the lower fares and greater range of services offered by commercial aviation following deregulation may have also contributed to the decline. 


\subsection{Overall Risk}

Another way of looking at trends in modal risk over time is to calculate the annual probability that a random member of society will be fatally injured. Figure 11 shows per capita trend lines for four modes: highways, mainline railroads, maritime and aviation. The data have been normalized as indices with the modal risk in 1975 set equal to 100 .

Total highway fatalities (the bold line without markers) include all types of motorized users, pedestrians and bicyclists, but exclude fatalities that occur at highway-rail crossings. Total fatalities for railroads (the line with the square markers) include passengers, employees, crossing users, trespassers and bystanders. Maritime fatalities (the line with the star markers) include both recreational and commercial users. Aviation fatalities (the line with the circle markers) include crew, passengers, and bystanders on the ground for both scheduled and unscheduled commercial service and general aviation.

The per capita risk has declined continually and substantially in all modes of transportation. Between 1975 and 2010, highway risks have halved, railroad risks have declined by two-thirds, maritime risks by three-quarters, and aviation risks by almost four-fifths.

\section{Concluding Remarks}

By almost any measure, transportation is considerably safer now than it was in the mid 1970s. The improvement is especially noticeable for commercial modes such as aviation, railroads and maritime. Even the risks of private highway driving have halved during the past thirty-five years.

Yet there is no cause for complacency. There is continued public pressure for even more improvement. In part this is because transportation is, despite the improvement over time, a significant source of the risks that we face in our everyday lives. Transportation incidents are the largest source of "unintentional injury deaths" in the United States. They represent slightly less than four out of every ten such deaths, and are similar in magnitude to the combined sum of the victims of falls and poisonings, the next two leading causes.

A disproportionate part of the public debate concerns commercial transportation safety. The dramatic nature of crashes in commercial transportation, especially those that result in multiple fatalities or considerable environmental damage, engenders extensive press coverage and a public discussion as to the causes and what can be done to prevent a repetition. Yet highway crashes represent the vast majority (95\%) of the total transportation fatality risk. Despite the dramatic improvement in recent decades, 90 people die each day on the nation's highways. The motor vehicle must be the most dangerous machine that we interact with on a daily basis. 


\section{References}

Blattenberger, G., Fowles, R., Loeb, P.D., 2013. Determinants of motor vehicle crash fatalities using Bayesian model selection methods. Research in Transportation Economics XX(1), yyyzzz.

Bureau of Labor Statistics, annual. Census of Fatal Occupational Injuries. U.S. Department of Labor, Washington, DC.

Bureau of Transportation Statistics, annual. National Transportation Statistics. U.S. Department of Labor, Washington, DC.

Elvik, R., Høye, A., Vaa, T., Sørenson, M., 2009. The Handbook of Road Safety Measures. Second Edition. Emerald Group Publishing Limited, Bingley, UK.

Eno Transportation Foundation, 2007. Transportation in America. Twentieth edition. Eno Transportation Foundation, Washington, DC.

Evans, L., 2004. Traffic Safety. Science Serving Society, Bloomington Hills, MI.

Federal Aviation Administration, 2009. General Aviation and Air Taxi Activity Survey. U.S. Department of Transportation, Washington, DC.

Federal Highway Administration, annual. Highway Statistics. U.S. Department of Transportation, Washington, DC.

Federal Motor Carrier Safety Administration, annual. Large Truck and Bus Crash Facts. U.S. Department of Transportation, Washington, DC.

Federal Railroad Administration, annual. Railroad Safety Statistics. U.S. Department of Transportation, Washington, DC.

Federal Transit Administration, 2003. National Transit Database - Safety and Security Report for 2002. U.S. Department of Transportation, Washington, DC.

Federal Transit Administration, 2009. 2009 Rail Safety Statistics Report for 2003-2008. U.S. Department of Transportation, Washington, DC.

Federal Transit Administration, 2010. National Transit Database - Safety and Security Report for 2009. U.S. Department of Transportation, Washington, DC.

Fuller, J.K., Savage, I., 2012. Analysis of Non-Motorized Rail Fatalities in Metropolitan Chicago 2004-11. Working paper. Northwestern University, Evanston, IL.

George, B.F., 2008. Rail Trespasser Fatalities: Developing Demographic Profiles. Report to the Federal Railroad Administration. Cadle Creek Consulting, Edgewater, MD. 
Haddon Jr., W., 1972. A logical framework for categorizing highway safety phenomena and activity. Journal of Trauma 12(1), 193-207.

International Transport Forum, 2011. Road Safety Annual Report 2011. International Transport Forum, Paris.

Kochanek, K.D., Xu, J., Murphy, S.L., Miniño, A.M., Kung, H-C, 2011. Deaths: Preliminary data for 2009. National Vital Statistics Reports 59(4). National Vital Statistics System, Centers for Disease Control and Prevention, U.S. Department of Health and Human Services.

Miniño, A.M., Xu, J., Kochanek, K.D., 2010. Deaths: Preliminary data for 2008. National Vital Statistics Reports 59(2). National Vital Statistics System, Centers for Disease Control and Prevention, U.S. Department of Health and Human Services.

Mok, S., Savage, I. 2005. Why has safety improved at rail-highway grade crossings? Risk Analysis 25(4), 867-881.

National Highway Traffic Safety Administration, annual. Traffic Safety Facts. U.S. Department of Transportation, Washington, DC.

National Highway Traffic Safety Administration, 2010. Seat Belt Use in 2009-Use Rates in the States and Territories. Report DOT-HS-811-324. U.S. Department of Transportation, Washington, DC.

National Safety Council, annual. Injury Facts. National Safety Council, Itasca, IL

National Transportation Safety Board, annual-a. Annual Review of Aircraft Accident Data, U.S. Air Carrier Operations. National Transportation Safety Board, Washington, DC.

National Transportation Safety Board, annual-b. Annual Review of Aircraft Accident Data, U.S. General Aviation. National Transportation Safety Board, Washington, DC.

Oster Jr., C.V., Strong, J.S., 2013. Analyzing road safety in the United States. Research in Transportation Economics XX(1), yyy-zzz.

Oster Jr., C.V., Strong, J.S., Zorn, C.K., 1992. Why Airplanes Crash: Aviation Safety in a Changing World. Oxford University Press, New York.

Oster Jr., C.V., Strong, J.S., Zorn, C.K., 2013. Analyzing aviation safety: problems, challenges, opportunities. Research in Transportation Economics XX(1), yyy-zzz.

Savage, I.,2006. Does public education improve rail-highway crossing safety? Accident Analysis and Prevention 38(2), 310-316. 
Savage, I., 2007. Trespassing on the railroad. Research in Transportation Economics 20(1), 199224.

United States Army Corp of Engineers, annual. Waterborne Commerce of the United States. U.S. Army Corp of Engineers, Alexandria, VA:.

United States Coast Guard, annual. Boating Statistics. U.S. Department of Homeland Security, Washington, DC.

\section{Appendix: Data Sources}

\section{Comparison with Other Fatal Injury Risks}

The National Safety Council's (NSC) annual Injury Facts is a compendium of data on fatal and non-fatal injury risks (National Safety Council, annual). This publication has definitive data based on analyses of death certificates for earlier years and estimates the number of deaths, categorized by cause, in recent years (the 2011 edition has estimates for 2008 and 2009). Definitive aggregate data on the number of deaths in 2008 and 2009 is available from the Centers for Disease Control and Prevention's National Vital Statistics Reports (Miniño et al, 2010; Kochanek et al, 2011).

\section{Highway}

The National Highway Traffic Safety Administration's (NHTSA) Fatality Analysis Reporting System (FARS) is the primary source for all highway fatality data (National Highway Traffic Safety Administration, annual). The data is reported in the annual Traffic Safety Facts publication. This publication contains a wealth of information on the circumstances of crashes, and the driver and vehicle(s) involved. FARS data excludes known suicides. Data are also available on NHTSA's FARS web site, which permits the user to request data cross-tabulations. Detailed information on the types of highway users involved in collisions at rail-highway grade crossings is also available from the Federal Railroad Administration (FRA) databases (see the railroad section).

Analysis of crash involvement by heavy trucks can be found in the Federal Motor Carrier Safety Administration's annual Large Truck and Bus Crash Facts, and its predecessor Large Truck Crash Facts (Federal Motor Carrier Safety Administration, annual). The source of this data is the FARS database.

Exposure data is available from the FHWA's annual Highway Statistics publication (Federal Highway Administration, annual). Vehicle miles and passenger miles categorized by vehicle type are shown in table VM-1. Vehicle miles by highway type are shown in table VM202. In 2009 the FHWA changed their algorithm for determining the share of total vehicle miles by vehicle type. Because of the radical changes, the crash and fatality rates for individual vehicle types is not comparable with early years. 
The FARS database defines a fatality as a death occurring within 30 days of a crash. FARS also only covers crashes that occur on a public highway and thereby excludes motor vehicle deaths that occur in parking lots, on private roads and in driveways. The NSC's annual Injury Facts publication analyses death certificates. They use a one year cut-off from the date of the crash for a death to count as a motor vehicle fatality, and include motor vehicle deaths on private land. The NSC estimates that FARS underestimates motor vehicle-related deaths by about 2,100 a year.

\section{Mainline Railroads}

Both fatality and exposure data (employee hours, train miles, passenger miles) for mainline railroads are obtained from the FRA's annual Railroad Safety Statistics publication (Federal Railroad Administration, annual) and its predecessor publications Accident/Incident Bulletin and Highway-Rail Crossing Accident/Incident Bulletin and Inventory Bulletin. The data is also available on the FRA's web site.

\section{Maritime}

Data on recreational boating deaths is reported in the United States Coast Guard's (USCG) annual Boating Statistics (U.S. Coast Guard, annual) This publication also shows the number of registered private recreational vessels (this understates boat ownership as most small craft such as kayaks, canoes and row boats do not have to be registered).

Information on incidents on commercial vessels is reported to the USCG and recorded in the Marine Safety Management Information System database (CASMAIN) in the period to 2001 and Marine Information for Safety and Law Enforcement System (MISLE) database from 2002. Aggregate fatalities are reported in the Bureau of Transportation Statistics' (BTS) annual National Transportation Statistics publication (Bureau of Transportation Statistics, annual). Data on individual incidents were downloaded from the CASMAIN and MISLE databases, available on the USCG's web page, to determine the relative number of employee and passenger fatalities. The BTS annual National Transportation Statistics publication provides information on the number of large commercial vessels registered in the United States. The U.S. Army Corp of Engineers' annual Waterborne Commerce of the United States (U.S. Army Corp of Engineers, annual) provides information on the number of ton-miles of commercial cargo carried by United States and foreign-flagged vessels in United States territorial waters (the whole of the Great Lakes are considered U.S. waters for the purposes of this calculation).

Data on fatalities on ferry boats, and the number of passenger miles of travel, were obtained from the Federal Transit Administration's (FTA) National Transit Database (NTD).

\section{Aviation}

The National Transportation Safety Board (NTSB) is the reporting agency for all types of aviation incidents. They publish statistical summaries in an annual press release, and in two annual publications Annual Review of Aircraft Accident Data, U.S. Air Carrier Operations (National Transportation Safety Board,annual-a) and Annual Review of Aircraft Accident Data, 
U.S. General Aviation (National Transportation Safety Board, annual-b). The NTSB publications also contain information on exposure to crashes (aircraft departures, passenger enplanements, aircraft hours, passenger miles) based on data reported to the Federal Aviation Administration and the BTS. Since 1997 commercial aircraft with more than 10 seats are regulated and identified as "Part 121 " operations, and those with less than ten seats as "Part 135.” Prior to 1997 the boundary between these two types of operations was 30 seats.

\section{Rail Transit}

Local transit is primarily regulated at the state level. The data for our analysis is drawn from information reported by transit agencies to the FTA's NTD, and from information reported to the FTA from state safety oversight agencies. Data were obtained from the FTA National Transit Database - Safety and Security Report for 2002 and 2009 (Federal Transit Administration, 2003, 2010), and the FTA’s 2009 Rail Safety Statistics Report for 2003-2008 (Federal Transit Administration, 2009).

\section{Pipelines}

Pipeline fatalities are reported in the BTS annual National Transportation Statistics publication based on information collected by the Pipeline and Hazardous Materials Safety Administration (Bureau of Transportation Statistics, annual).

\section{Workplace Fatalities and Injuries}

Workplace fatalities are reported to the Bureau of Labor Statistics (BLS) as part of the Census of Fatal Occupational Injuries (Bureau of Labor Statistics, annual). The data are available on the BLS website.

\section{Population}

Population data is the mid-year (July 1) estimate of the United States Resident population made by the Census Bureau, and is available on their web site. 
Table 1: Average Annual Fatalities in the United States 2000-2009

\begin{tabular}{|c|c|c|c|c|c|c|}
\hline & \multicolumn{3}{|c|}{ Private Transportation } & \multicolumn{3}{|c|}{ Commercial Transportation } \\
\hline & $\begin{array}{c}\text { Crashes } \\
\text { solely } \\
\text { involving } \\
\text { private users }\end{array}$ & $\begin{array}{c}\text { Crashes with } \\
\text { commercial } \\
\text { highway } \\
\text { carriers }\end{array}$ & $\begin{array}{c}\text { Crashes with } \\
\text { commercial } \\
\text { non-highway } \\
\text { carriers }\end{array}$ & Passengers & Employees & Bystanders \\
\hline \multicolumn{7}{|c|}{ Highway Modes } \\
\hline $\begin{array}{l}\text { Cars and } \\
\text { light trucks }\end{array}$ & 26,678 & 3,766 & $245^{\mathrm{a}}$ & $7^{b}$ & $9^{b}$ & n.a \\
\hline $\begin{array}{l}\text { Pedestrians \& } \\
\text { bicycles }\end{array}$ & 4,930 & 545 & $592^{c}$ & n.a & n.a & n.a \\
\hline Motorcycles & 3,989 & 156 & $2^{\mathrm{a}}$ & n.a & n.a & 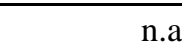 \\
\hline Large Trucks & n.a & n.a & n.a & n.a & 724 & $\overline{\text { n.a }}$ \\
\hline Buses & n.a & n.a & n.a & 30 & 9 & n.a \\
\hline \multicolumn{7}{|c|}{ Non-Highway Modes } \\
\hline Maritime & 704 & 0 & 1 & 42 & 85 & 1 \\
\hline Aviation $^{\mathrm{d}}$ & 548 & 0 & 1 & 74 & 21 & 2 \\
\hline Railroads & n.a & n.a & n.a & 7 & 27 & 4 \\
\hline Rail Transit & n.a & n.a & n.a & 22 & 3 & 0 \\
\hline Pipeline & n.a & n.a & n.a & n.a & 5 & 12 \\
\hline \multicolumn{7}{|c|}{ Totals } \\
\hline Total & 36,849 & 4,467 & 839 & 182 & 883 & 19 \\
\hline U.S. Total & \multicolumn{6}{|c|}{43,239} \\
\hline
\end{tabular}

Notes: $\quad$ n.a. $=$ not applicable

${ }^{a}$ collisions with trains and rail transit vehicles at highway-rail grade crossings

${ }^{\mathrm{b}}$ taxi and limousine occupants

c $11 \%$ result from collisions with trains and rail transit vehicles at highway-rail grade crossings. $89 \%$ are pedestrian trespassers elsewhere on the railroad. These data exclude suicides. Suicides on rail transit lines averaged 22 a year. During this time period suicidal acts on mainline railroads were not reportable. It is suspected that there are 220-245 unreported annual suicides on mainline railroads.

${ }^{\mathrm{d}}$ aviation deaths exclude those caused by suicide, sabotage and terrorism.

Sources: See appendix 
Table 2: Passenger Fatalities per Billion Passenger Miles 2000-2009

\begin{tabular}{|l|c|}
\hline Riding a motorcycle & 212.57 \\
\hline Driving or passenger in a car or light truck & 7.28 \\
\hline Passenger on a local ferry boat & 3.17 \\
\hline Passenger on commuter rail and Amtrak & 0.43 \\
\hline $\begin{array}{l}\text { Passenger on urban mass transit rail (2002- } \\
\text { 2009) }\end{array}$ & 0.24 \\
\hline $\begin{array}{l}\text { Passenger on a bus (holding more than 10 } \\
\text { passengers - transit, intercity, school, charter) }\end{array}$ & 0.11 \\
\hline Passenger on commercial aviation & 0.07 \\
\hline
\end{tabular}

Notes: ${ }^{\mathrm{a}}$ While onboard a train including assault and violent acts

Sources: See appendix

Table 3: Workplace Fatality Rate per 1,000 Employees 2009 with comparison to other non-transportation industry segments in italics

\begin{tabular}{|l|c|c|}
\hline & $\begin{array}{c}\text { NAICS } \\
\text { Classification }\end{array}$ & $\begin{array}{c}\text { Fatality } \\
\text { Rate }\end{array}$ \\
\hline Fishing & 1141 & 8.81 \\
\hline Agriculture & $111 / 112$ & 0.76 \\
\hline Taxi and limousine & 4853 & $0.62^{\text {a }}$ \\
\hline Truck transportation & 484 & 0.29 \\
\hline Water transportation & 483 & 0.24 \\
\hline Mining & 21 & 0.14 \\
\hline Construction & 23 & 0.12 \\
\hline Pipeline transportation & 486 & 0.10 \\
\hline Urban transit & 4851 & 0.10 \\
\hline Rail transportation & 482 & 0.06 \\
\hline Air transportation & 481 & 0.06 \\
\hline Couriers and messengers & 492 & 0.05 \\
\hline Utilities & 22 & 0.03 \\
\hline $\begin{array}{l}\text { Interurban and rural bus, school bus, charter bus, } \\
\text { other transit and ground passenger transportation }\end{array}$ & $4852 / 4 / 5 / 9$ & 0.03 \\
\hline Manufacturing & $31 / 32 / 33$ & 0.03 \\
\hline Warehousing and Storage & 493 & 0.02 \\
\hline
\end{tabular}

Notes: $\quad$ NAICS = North American Industry Classification System

a $55 \%$ of fatalities to taxi and limousine employees are due to assaults and violent acts Source: Bureau of Labor Statistics 


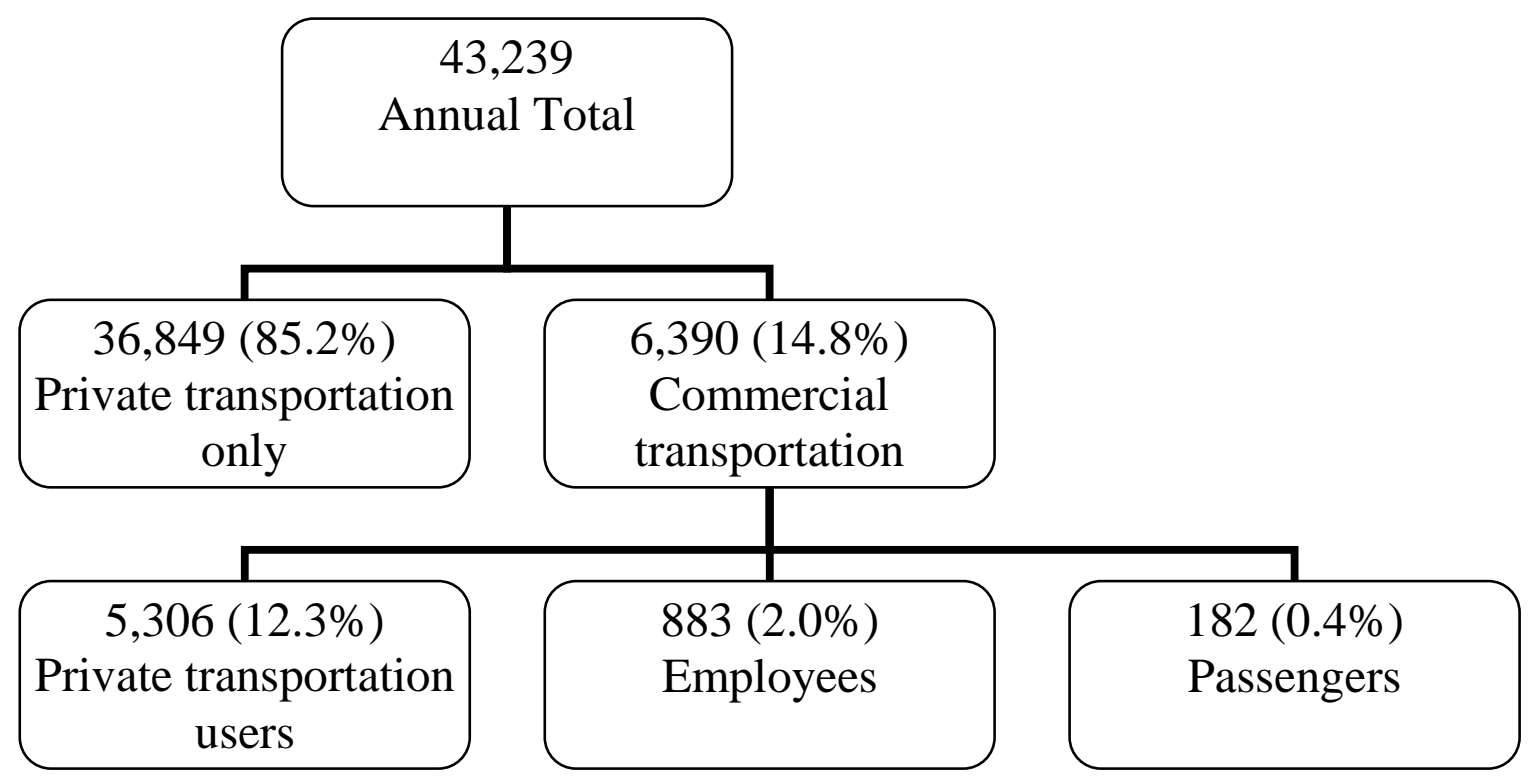

Figure 1: Categorization of average annual fatalities 2000-2009 


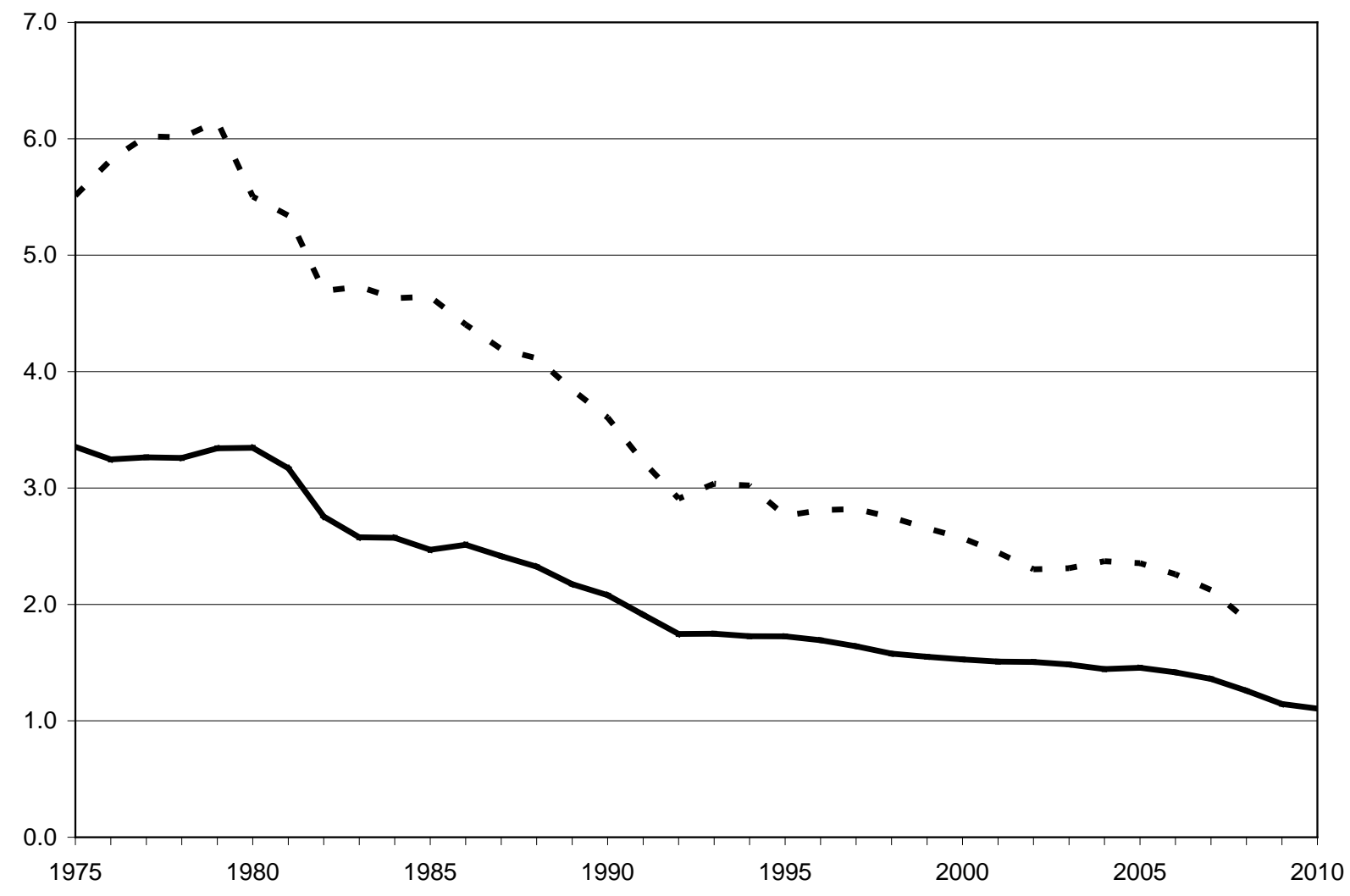

Figure 2: Highway Fatality Rates for All Motor Vehicles per 100 Million Vehicle Miles Traveled (solid line) 1975-2010 and in Large Truck Involved Crashes per 100 Million Truck Miles (dashed line) 1975-2008 


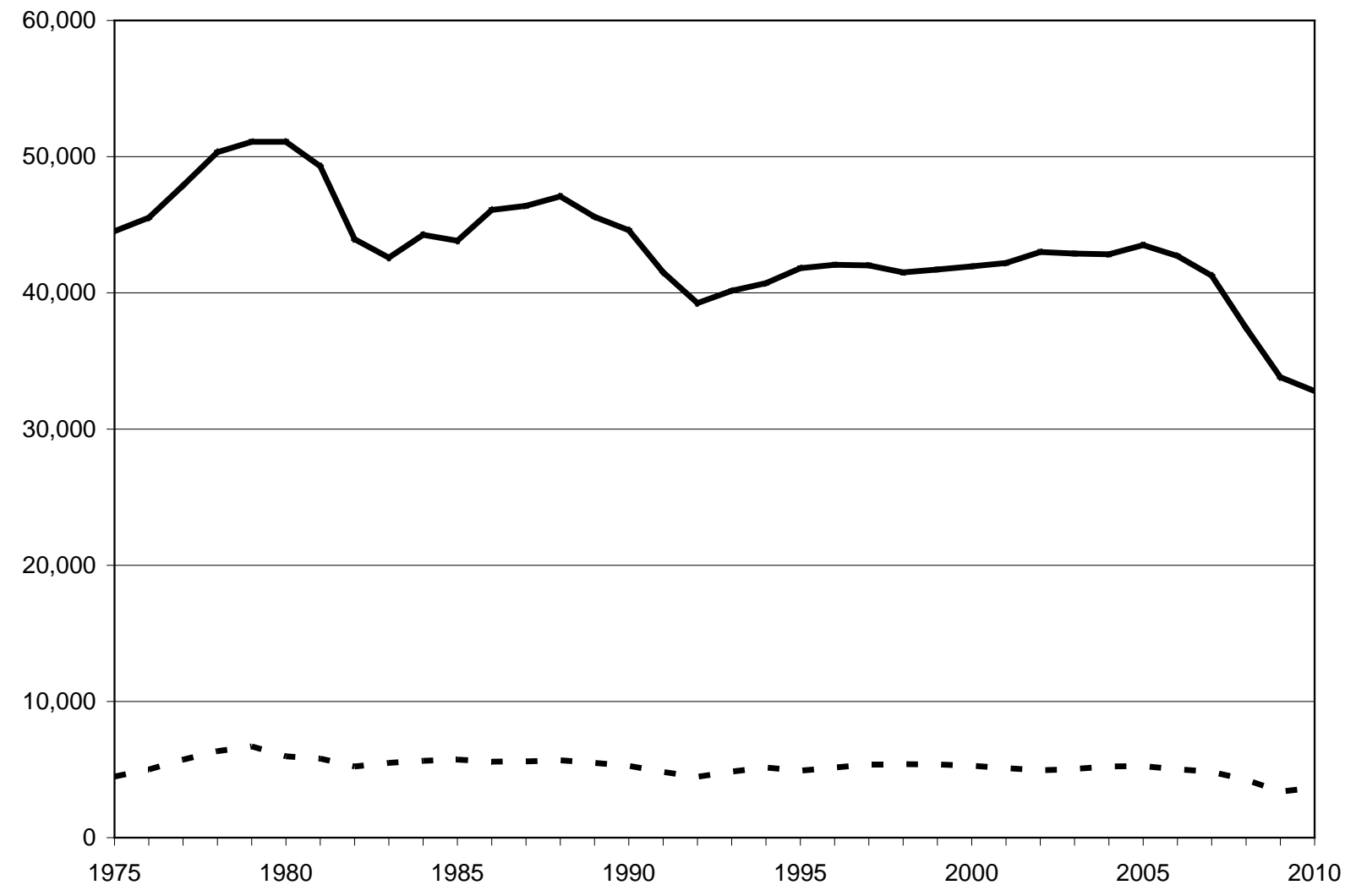

Figure 3: Total Highway Fatalities (solid line) and Fatalities in Large Truck Involved Crashes (dashed line) 1975-2010 


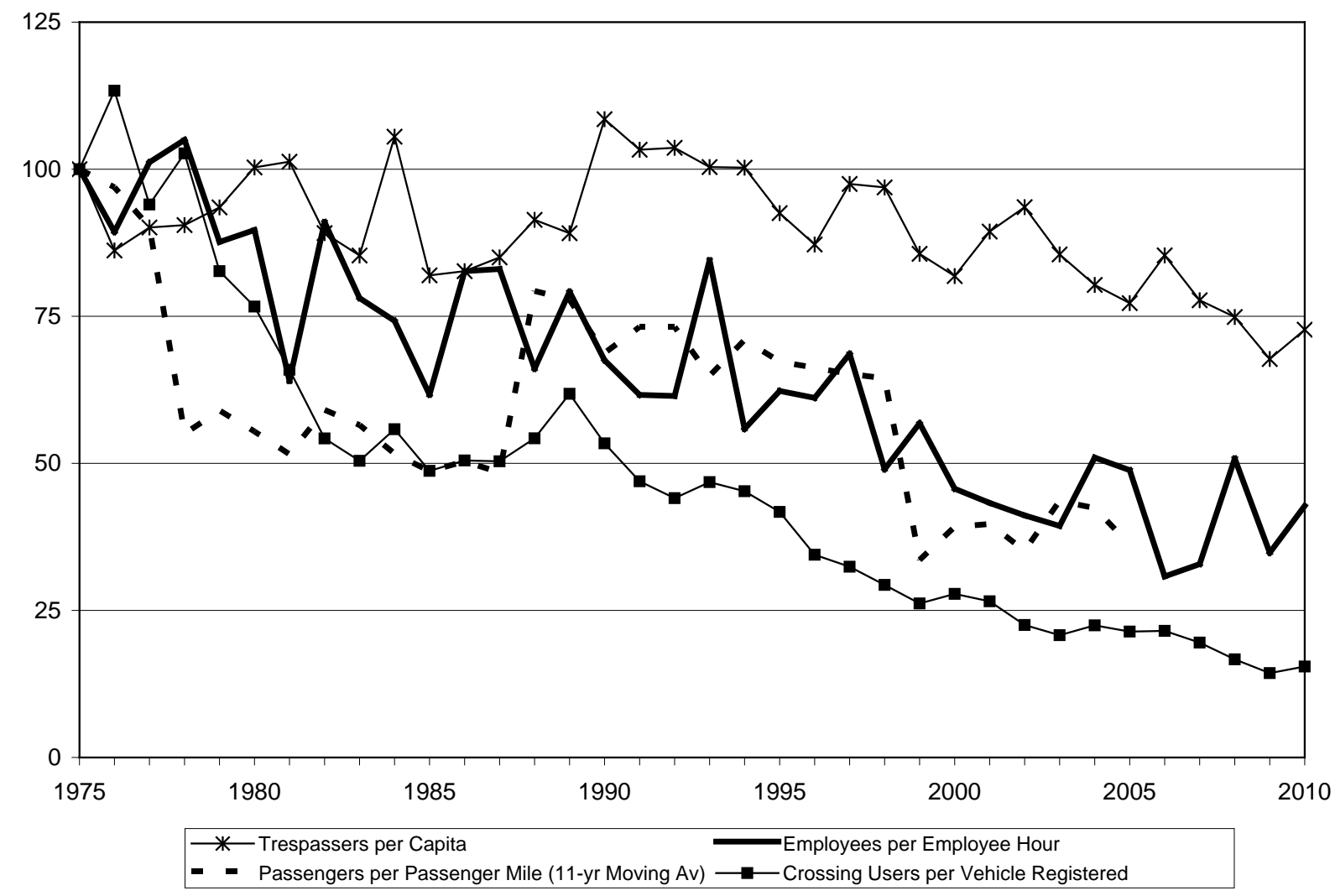

Figure 4: Indices of Railroad Fatality Rates 1975-2010 with $1975=100$ 


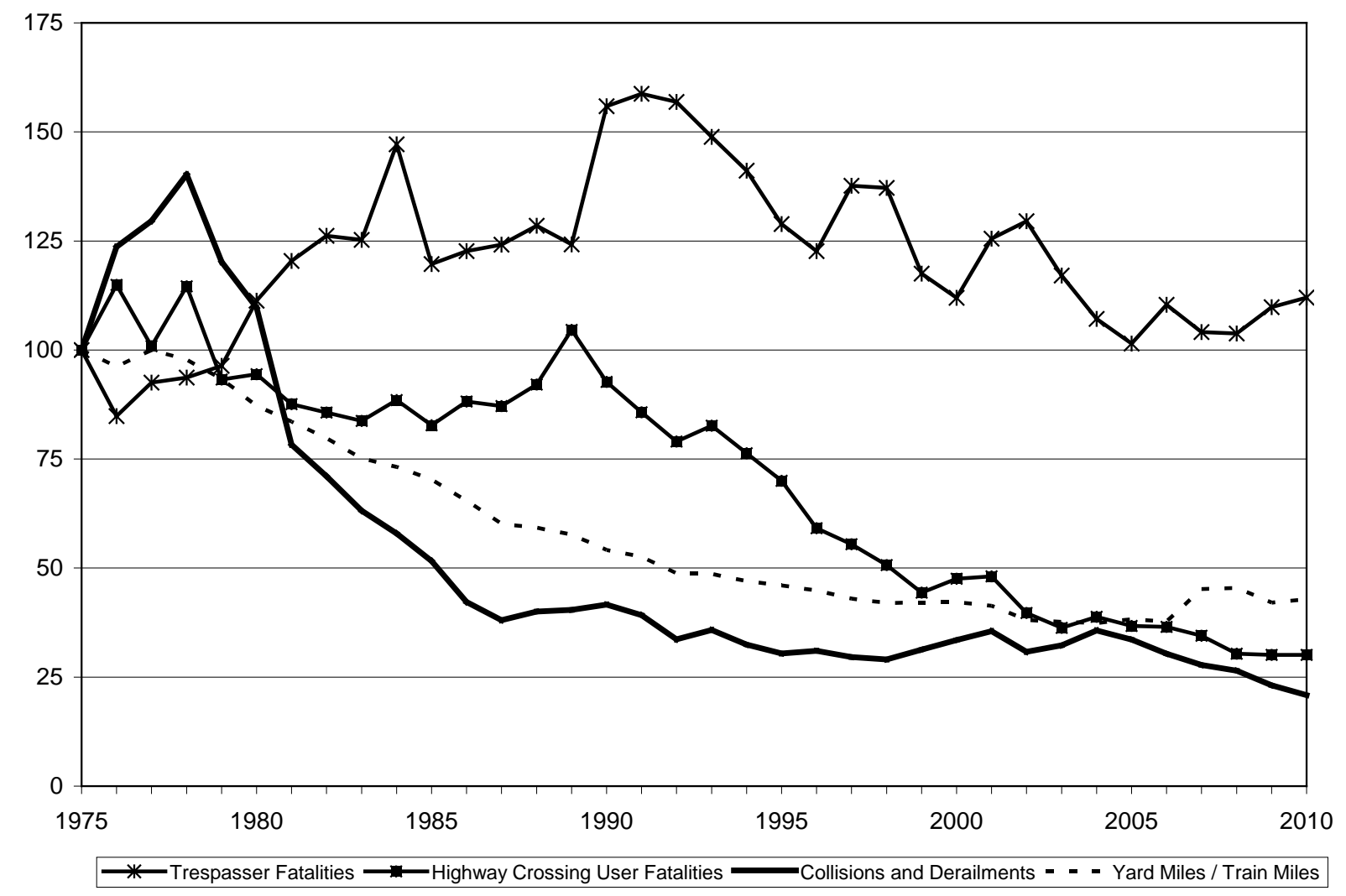

Figure 5: Indices of Railroad Safety Rates per Train Mile 1975-2010 with $1975=100$ and the Ratio of Yard Miles to Total Train Miles 


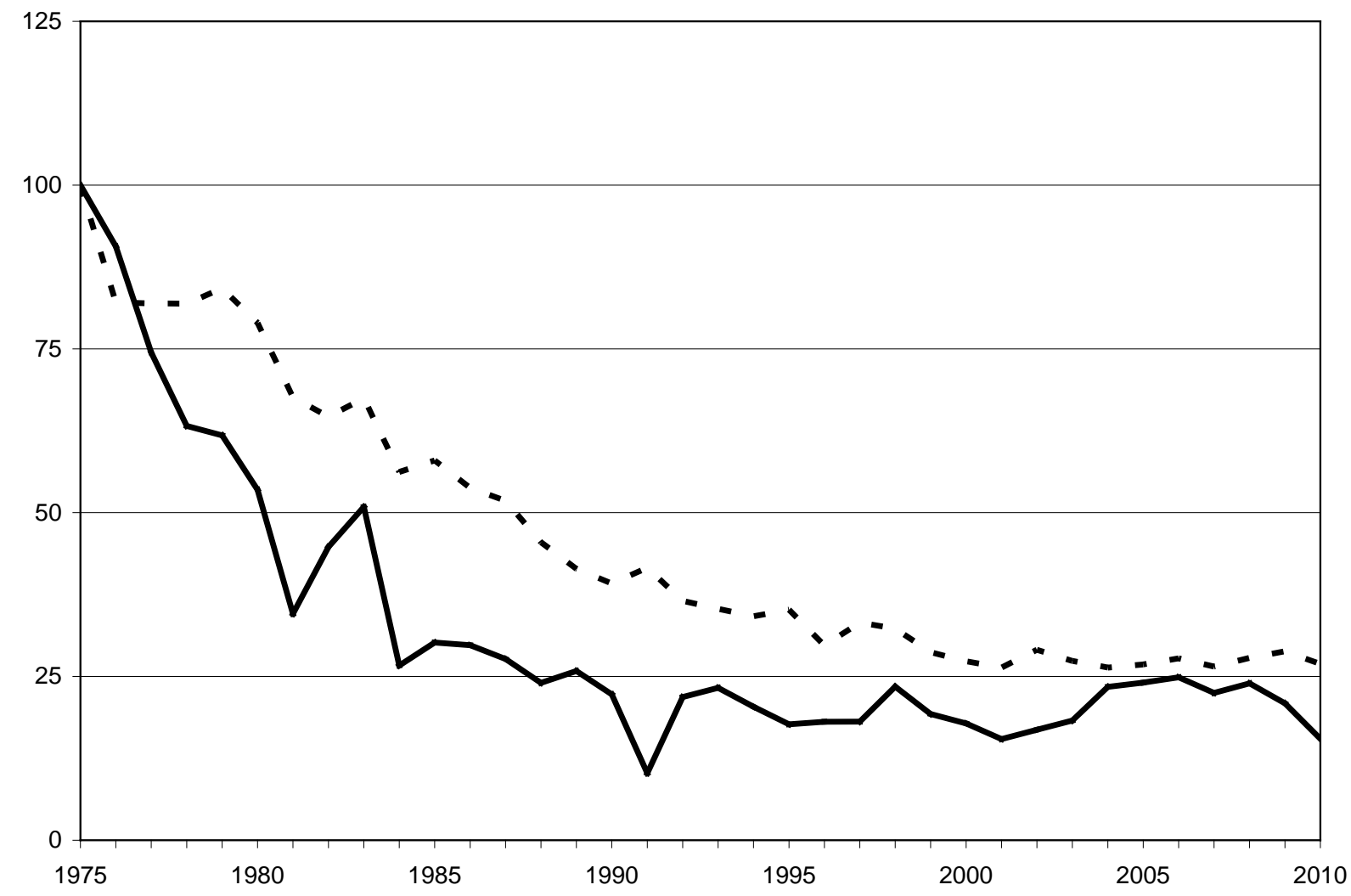

Figure 6: Indices of Maritime Fatality Rates 1975-2010 with $1975=100$. Commercial Maritime Fatalities per Cargo Ton Mile (solid line) and Recreational Fatalities per Registered Vessel (dashed line) 


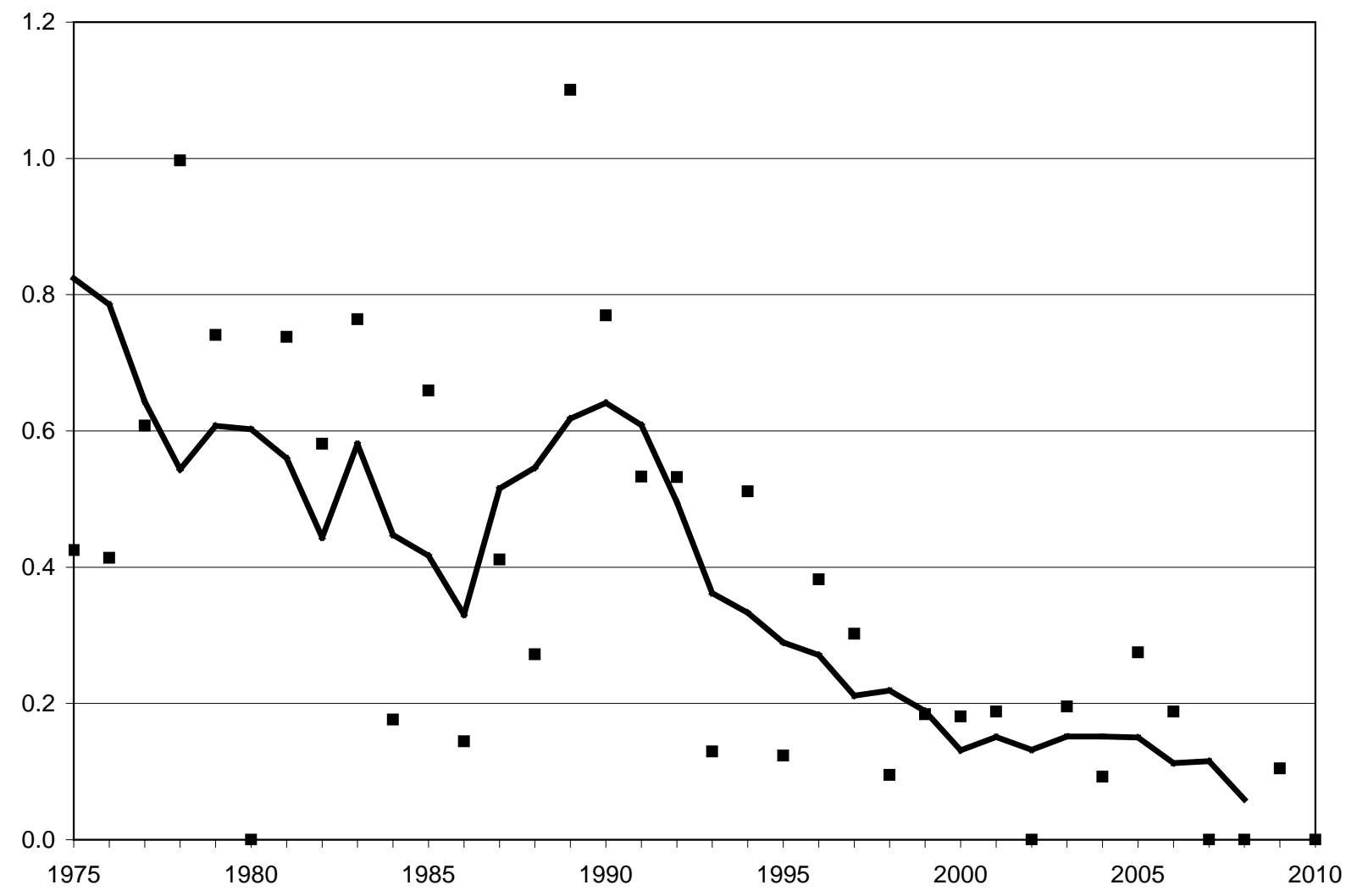

Figure 7: Aviation Fatal Accidents per Million Departures 1975-2010 (squares) with 5Year Moving Average (solid line) for Part 121 Scheduled Service 


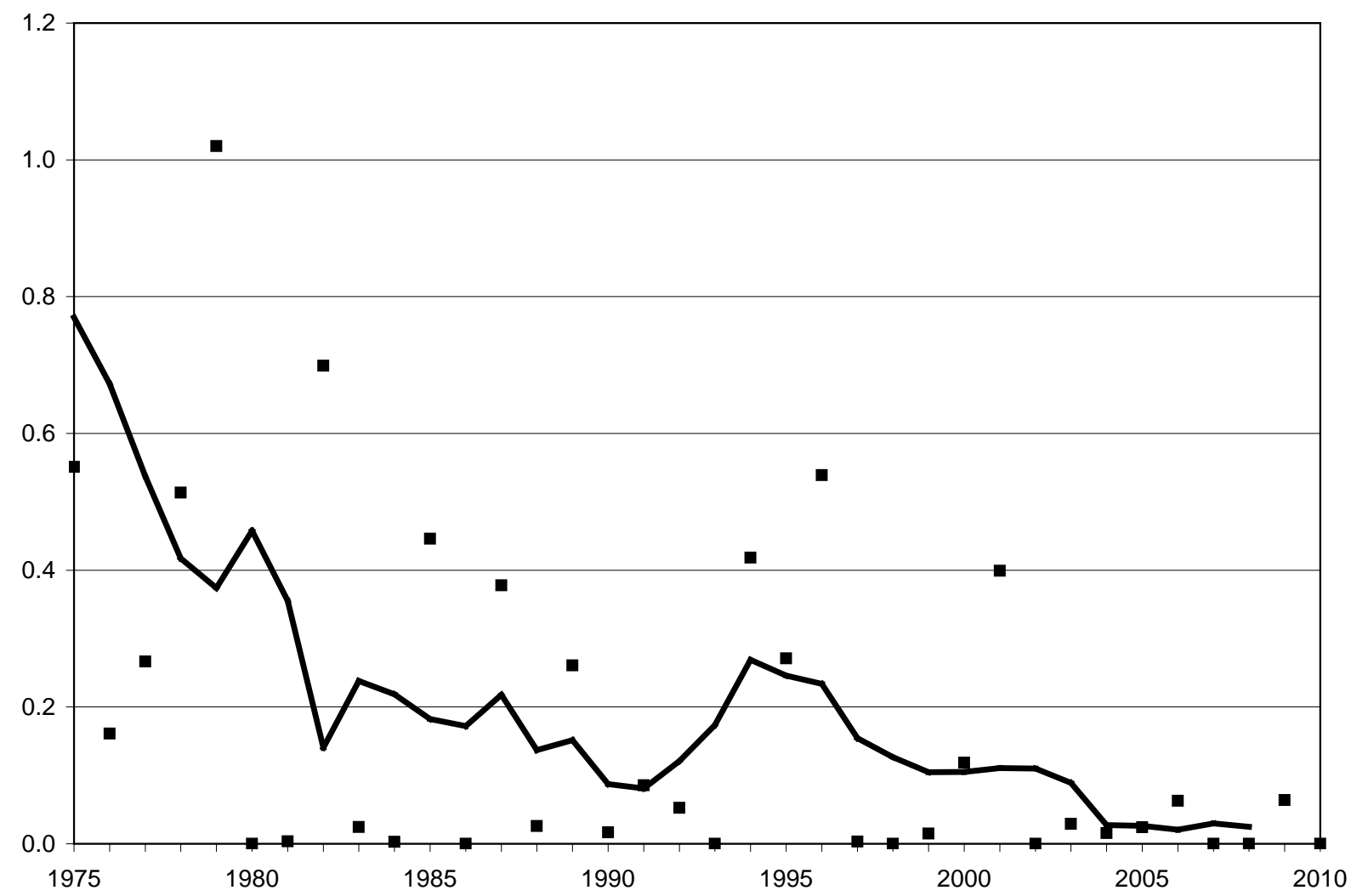

Figure 8: Aviation Passenger Fatalities per Million Passenger Enplanements 1975-2010 (squares) with 5-Year Moving Average (solid line) for Part 121 Scheduled Service 


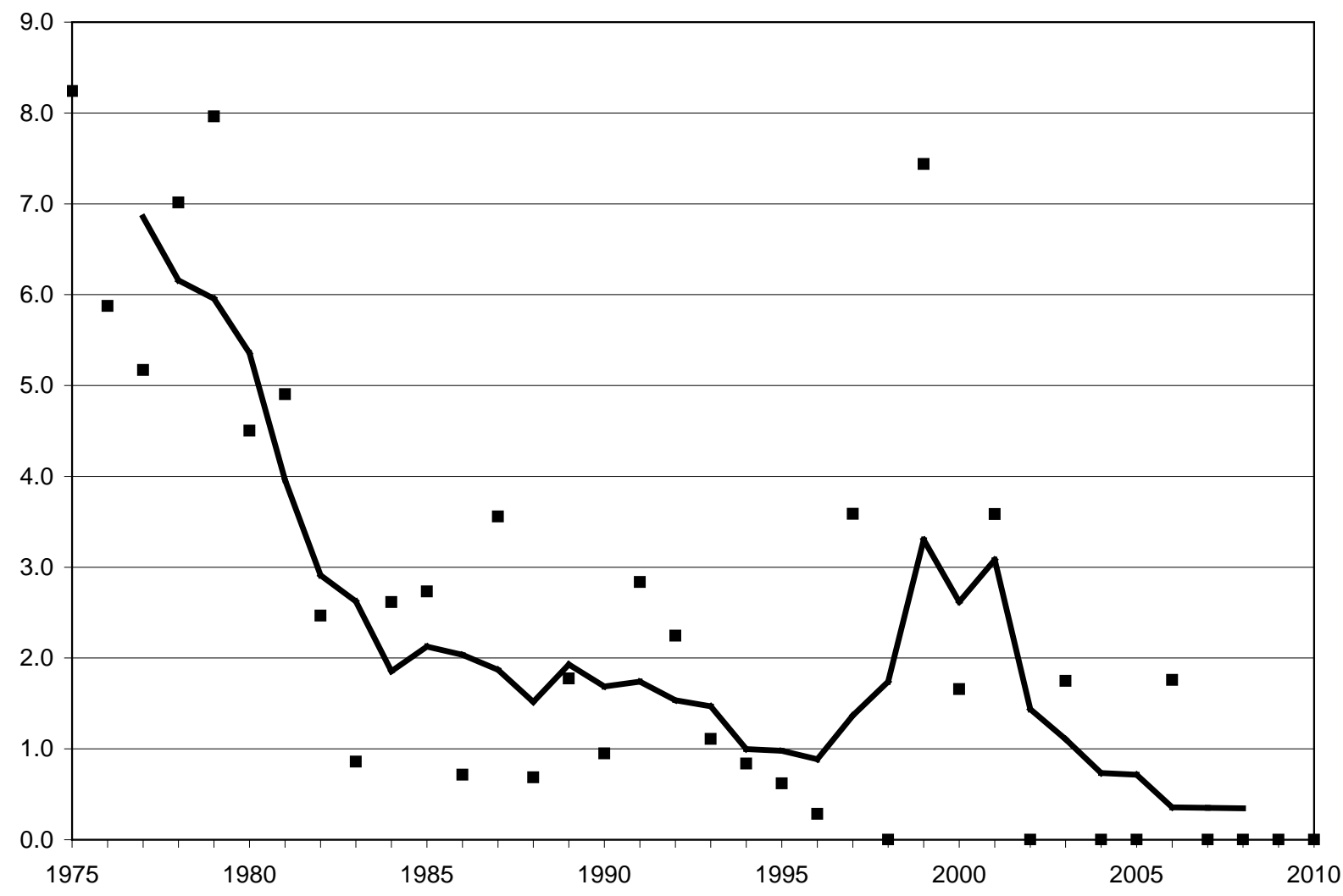

Figure 9: Aviation Fatal Accidents per Million Departures 1975-2010 (squares) with 5Year Moving Average (solid line) for Part 135 Scheduled Service 


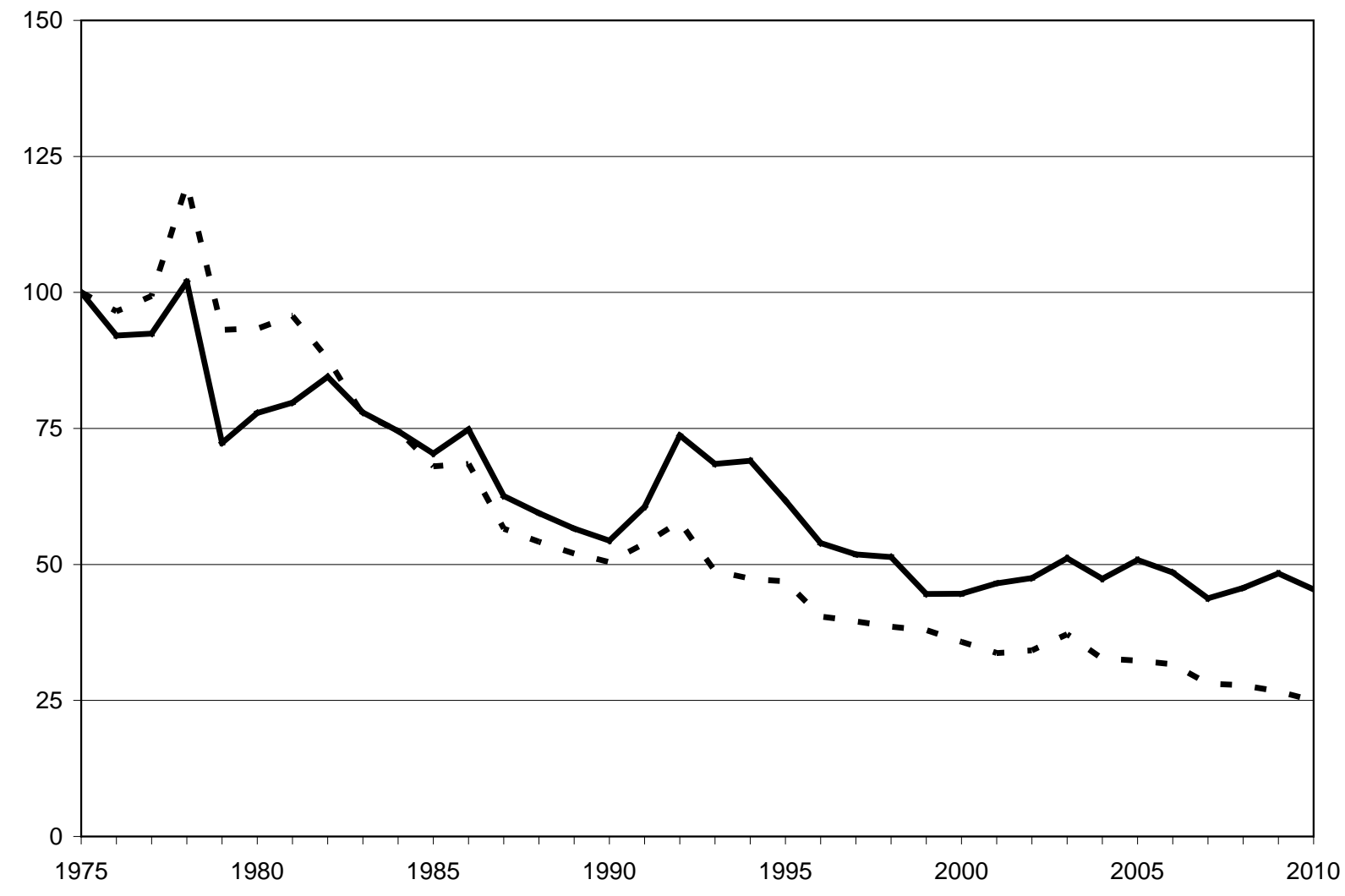

Figure 10: Indices of General Aviation Fatalities per Aircraft Hour (solid line) and per Capita (dashed line) 1975-2010 with $1975=100$ 


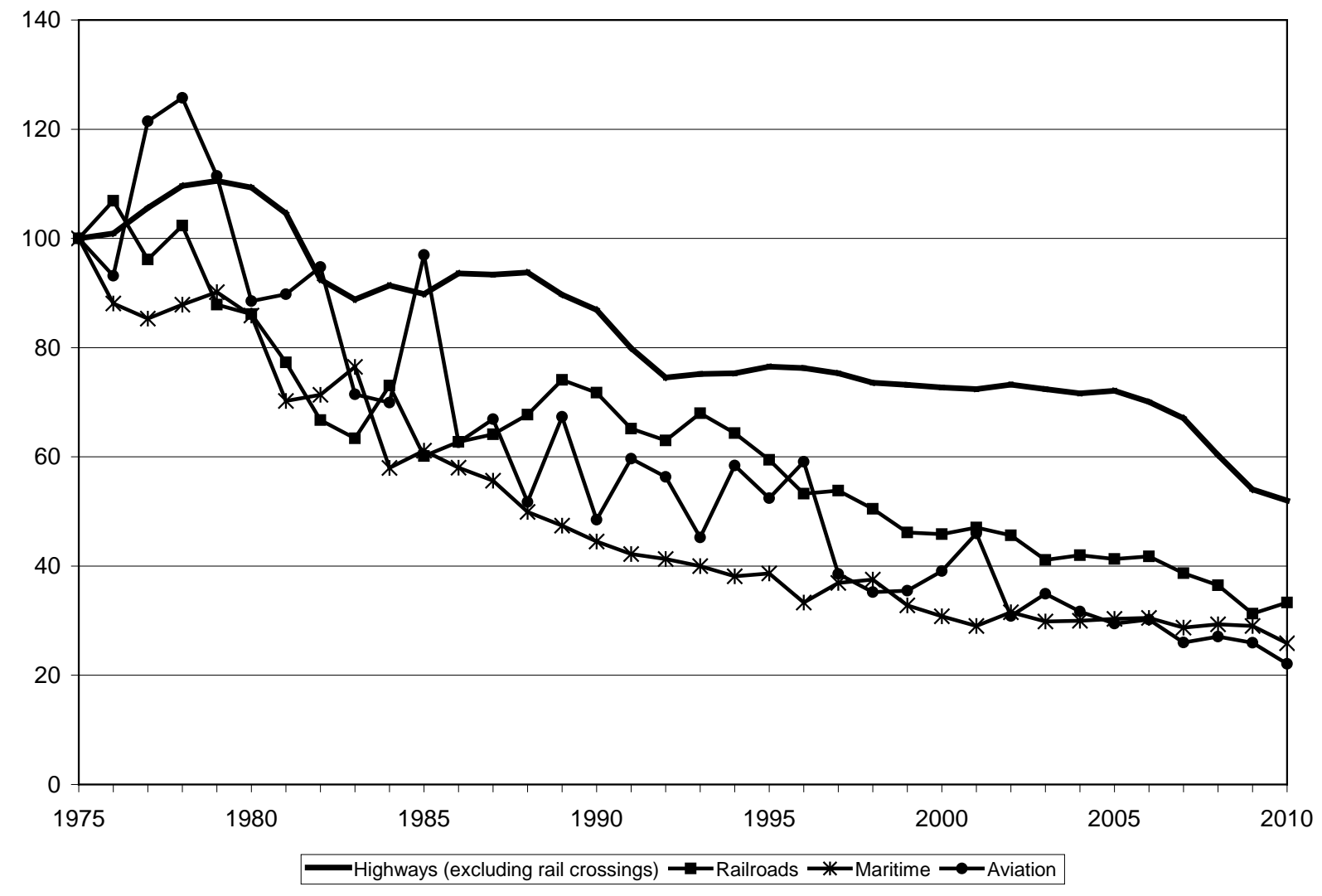

Figure 11: Indices of Time Trends in per Capita Fatality Rates 1975-2010 